\title{
Biological Roles of Peptidases in Trypanosomatids
}

\author{
Alane Beatriz Vermelho, ${ }^{*}$, Marta Helena Branquinha ${ }^{1}$, Claudia M. D’Ávila-Levy ${ }^{2}$, André Luis \\ Souza dos Santos ${ }^{1}$, Edilma Paraguai de Souza Dias ${ }^{1}$ and Ana Cristina Nogueira de Melo ${ }^{1}$
}

\author{
${ }^{1}$ Instituto de Microbiologia Prof. Paulo de Góes (IMPPG), Centro de Ciências da Saúde (CCS), Universidade Federal \\ do Rio de Janeiro (UFRJ), Bloco I, Ilha do Fundão, 21941-902, Rio de Janeiro, RJ, Brazil \\ ${ }^{2}$ Departamento de Bioquímica e Biologia Celular (DBBM), Instituto Oswaldo Cruz, Fundação Oswaldo Cruz, Mangui- \\ nhos, 21045-900, Rio de Janeiro, RJ, Brazil
}

\begin{abstract}
In this review, we report the recent developments in the characterization of peptidases and their possible biological functions in the Trypanosomatidae family. The focus will be on peptidases from Trypanosoma cruzi, Leishmania spp., African trypanosomes and plant and insect trypanosomatids. There are numerous events in parasite development where the involvement of peptidases has been established, and they will be approached in the present review. Also in this review we will discuss the central roles have been proposed for peptidases in diverse processes such as virulence, host cell interaction and invasion, catabolism of host proteins, differentiation, cell cycle progression and both stimulation and evasion of host immune responses.
\end{abstract}

Keywords: Peptidases, Trypanosomatids, Cruzipain, Cysteine peptidases, Serina peptidases, Metallopeptidases.

\section{INTRODUCTION}

Trypanosomatids are flagellate protozoa of the Kinetoplastida order, which is characterized by the presence of kinetoplast DNA (kDNA), an extracellular DNA network of circular molecules composed by maxi- and minicircles that corresponds to the parasite mitochondrial genome, localized near the basal body [1]. The Kinetoplastida order includes the Trypanosomatidae family, an exclusively parasitic taxon that infects a wide range of animals and plants and the Bodonidae family that includes parasitic and exclusively freeliving organisms $[1,2]$.

The Trypanosomatidae family comprises four genera of digenetic organisms that parasitize vertebrate (Trypanosoma, Leishmania and Endotrypanum) or plant (Phytomonas) hosts, with insects or leeches serving as vectors and the monogenetic genera (Leptomonas, Crithidia, Blastocrithidia, Herpetomonas and Rhynchoidomonas) that are found largely in hemipteran and dipteran insect vectors with a limited distribution in seven other orders of insects, as well as in ciliates $[2,3]$. Although the Trypanosomatidae family infects a diverse range of hosts, only two genera, Leishmania and Trypanosoma, are found in humans and are etiologic agents of important diseases such as leishmaniasis, Chagas' disease and African trypanosomiasis [3]. These trypanosomiases are neglected tropical diseases, since they are largely ignored by medical science, first-world public opinion and pharmaceutical companies [4]. The monoxenous trypanosomatids have been used as comparative models of study in order to understand the physiology, biochemistry, ultrastructure and the

\footnotetext{
*Address correspondence to this author at the Departamento de Microbiologia, Geral, Instituto de Microbiologia Prof. Paulo de Góes, Universidade Federal do, Rio de Janeiro-UFRJ /CCS, Bloco I, Cidade Universitária, Ilha do Fundão, Rio, de Janeiro, R.J, Brazil; CEP: 21941-902, Tel: (021) 25626743; Fax: (021) 25608344; E-mail: abvermelho@micro.ufrj.br
}

molecular biology of the pathogenic species [5-30]. In addition, trypanosomatids that are not normally infectious to humans have been isolated from immunosuppressed patients, mainly in HIV-positive individuals, where these parasites caused either visceral or cutaneous lesions [31].

Trypanosoma cruzi is the causative protozoan parasite of Chagas' disease, a debilitating and incurable chronic inflammatory condition characterized by cardiomyopathy and/or digestive disorders [32]. Its life cycle involves the obligatory passage through vertebrate mammals and invertebrate hematophagous triatomine bug hosts. The trypomastigotes ingested by the insect vector differentiate into proliferative epimastigotes that, on reaching the posterior intestine, evolve into metacyclic trypomastigotes. These forms invade vertebrate host cells and differentiate into non-flagellated amastigotes, which in turn transform into trypomastigotes that are responsible for the dissemination of the infection $[33,34]$. Chagas' disease is endemic in Latin America and it affects an estimated 16-18 million people mainly in Central and South America, causing up to 45,000 deaths each year [35]. Recent surveys indicate that about 200,000 new cases occur yearly in areas where the disease is endemic, representing the third most common parasitic infection worldwide after malaria and schistosomiasis [36]. Most human infections occur through contact with infected bloodsucking triatomine species. The urbanization process in Latin America and immigration trends, however, have led to the disease being diagnosed in non-endemic areas where, even in the absence of the vector the infection can still be transmitted congenitally, by blood transfusion and by organ transplantation. In addition, oral transmission has aroused the attention of researchers, due to outbreaks in some particular areas such as the Brazilian Amazon, mainly associated with the consumption of Amazonian palm berry or açaí (Euterpe oleracea Mart.) juice [37]. Recently, in December 2007, an 
outbreak of Chagas' disease occurred in Caracas, Venezuela, related to ingestion of contaminated fruit juices [38]. Despite vector-control programs, this disease is an important public health concern because no vaccines have been developed and there are no prophylactic drugs to prevent infection by $T$. cruzi. Currently available medication, such as nitrofurans (nifurtimox) and nitroimidazoles (benznidazole) are effective during the acute phase of the infection but have little effect in the chronic stage of the disease [39]. Moreover, in addition to serious side effects, resistance against both compounds leads to increasing treatment failures [40]. Within this framework, an intense research program has been directed to develop strategies to produce a vaccine or efficient non-toxic drugs, through the investigation of specific targets such as molecules, organelles and metabolic pathways in $T$. cruzi [41].

African trypanosomes are devastating human and animal pathogens. Trypanosoma brucei rhodesiense and T. b. gambiense subspecies cause the fatal human disease known as African sleeping sickness and it continues to pose a major threat to 60 million people in 36 countries in sub-Saharan Africa [42]. The disease is caused by protozoan parasites of the genus Trypanosoma and comes in two types: East African human trypanosomiasis caused by $T$. $b$. rhodesiense and the West African form caused by $T$. $b$. gambiense. T. brucei is transmitted by the tsetse fly and alternates between the bloodstream and insect life cycle stages that are adapted to survive in the mammalian host and the insect vector, respectively [43]. The four main drugs used for human African trypanosomiasis are all toxic, and melarsoprol, the only drug that is effective for both types of central nervous system disease, is so toxic that it kills $5 \%$ of patients who receive it. Eflornithine, alone or combined with nifurtimox, is being used increasingly as first-line therapy for gambiense disease [4].

Leishmaniasis has a wide spectrum of diseased manifestations; hence, it is considered as a group of diseases rather than a single disease itself. The three main clinical forms are visceral, mucocutaneous and cutaneous. According to global estimates there are about two million new cases a year [44] and results in 2.4 million disability-adjusted life years annually [45]. Leishmania spp., the causative organism of leishmaniasis, is a protozoan parasite that lives as a promastigote in the digestive tract of sandflies and as an amastigote in the phagolysosomes of mammalian macrophages. At least 20 species of Leishmania are known to infect humans and they are the cause of a wide spectrum of clinical manifestations resulting in substantial morbidity and mortality with $10 \%$ of the world's population at risk of infection [46]. The increase in the incidence of the disease, associated with higher morbidity rates, the spread of some forms of leishmaniasis to new geographical areas and LeishmaniaHIV co-infection, has become an important public health problem in the world [47].

The designation 'lower trypanosomatids' referrers to the parasites that possess a monoxenous life cycle style and are usually found in insect hosts but are not considered capable of causing parasitic diseases in vertebrates. 'Lower trypanosomatids' also refers to the species of trypanosomatids belonging to the Phytomonas genus, which circulate between a phytophagous vector and a plant [48]. The genus Phytomonas comprises plant flagellate trypanosomatids that are etiological agents of diseases affecting various fruits and plants, some of them causing great economical losses in agriculture. For instance, phloem-dwelling phytomonads cause acute and chronic yellowing of leaves in coffee plants, 'hartrot' in coconut palms and 'marchitez wilt' in oil palms, while the latex-associated $P$. françai is found associated with a disease known as "chochamento das raiízes", which means "empty roots", in the latex of cassava (Manihot esculenta Crantz); and the disease is characterized by poor root system development and general chlorosis of the aerial part of the plant [15, 49]. However, phytomonads also parasitize lactiferous plants without any apparent pathogenicity [50]. These parasites are transmitted by phytophagous hemipteran insects of the families Coreidae, Lygaeidae, Pyrrhocoridae and Pentatomidae [49]. In comparison to the pathogenic trypanosomatids belonging to the Leishmania and Trypanosoma genera, very modest attention has been given to their lower counterparts. Nevertheless, lower trypanosomatids have been used as organism models to studies concerning cell biology, biochemistry, nutrition, ultrastructure, symbiosis and genetic approaches in the Trypanosomatidae family $[48,51]$. Surprisingly, some genera of monoxenous lineage have been isolated from other hosts such as plants and mammals [31, 49].

Recent advances in our understanding of the biochemistry and molecular biology of the protozoa have focused attention on specific parasite molecules that are essential to the parasite life cycle or the pathogenesis of the diseases they produce. One group of enzymes that plays myriad roles in these processes is the parasite-derived peptidases [52, 53]. This review focuses on the role of peptidases from trypanosomatids, objecting the understanding of the biochemistry and cell biology of these molecules during the parasite life cycle or in the interaction with host cells.

\section{PEPTIDASES}

Peptidases are a group of enzymes whose catalytic function is to hydrolyze peptide bonds of proteins. Nowadays the MEROPS database is a source of information on peptidases and contains all properties and characteristics of these enzymes including origin, nomenclature and classification, inhibitors, substrates, amino acid sequences and the structure if known [54]. The name peptidase is preferred to proteases, but they are also called proteolytic enzymes or proteinases. There are two sets of subclasses of peptidases: the exopeptidases [EC 3.4.11-19], enzymes that cleave peptide bonds at the amino- or carboxy-terminus, and the endopeptidases [EC 3.4.21-24 and EC 3.4.99], which cleave peptide bonds internally in a polypeptide. Peptidases have recently been classified using three different methods: [i] by the chemical mechanism of catalysis represented by serine, cysteine, threonine, aspartic, glutamic or the metallo catalytic type and only a few remain of unknown catalytic type, [ii] by the details of the catalytic reaction, as they are invariably selective of the bonds they hydrolyze and [iii] by molecular structure and homology. The last classification is the most recent of the three methods; it depends on the data availability for amino acid sequences and three-dimensional structures [53]. 
The study of peptidase activities in protozoan parasites, trypanosomatids in particular, has attracted considerable attention over the last decade, since some of these enzymes play important roles in host/parasite interactions [52, 53], which include modulation of the host immune system, invasion, destruction of host tissues, parasite migration, growth and development and/or acquisition of essential nutrients for survival and proliferation required for continued infection $[52,53]$. Furthermore, these enzymes are considered virulence factors $[52,53]$. Therefore, they are promising targets for the design of antimicrobials against trypanosomatid diseases [39-41, 55]. In addition, the ability of lower trypanosomatids to express homologues of Leishmania and
Trypanosoma virulence factors seems to play essential roles in the nutrition as well as in the interaction with the insect epithelial cells. Table 1 summarizes the major peptidases found in trypanosomatids.

\section{PEPTIDASES IN TRYPANOSOMA CRUZI}

\section{Cysteine Peptidase Families}

Cysteine peptidases of $T$. cruzi have been implicated in a variety of biological events including nutrition, invasion of host cells, immune evasion, pathogenesis and virulence and some have also been validated as promising drug targets [52$55,56]$. The major cysteine peptidase of this parasite, the

Table 1. Major Peptidases of Trypanosomatids

\begin{tabular}{|c|c|c|}
\hline Trypanosomatids & Peptidase Class & Peptidase Name \\
\hline \multirow{5}{*}{ Trypanosoma cruzi } & Cysteine peptidases & $\begin{array}{c}\text { Cruzipain } \\
\text { Cathepsin B-like } \\
\text { Calpains } \\
\text { Metacaspases }\end{array}$ \\
\hline & Metallopeptidases & $\begin{array}{c}\text { Gp63 } \\
\text { Metallocarboxypeptidases (TcMCP-1 and TcMCP-2 ) } \\
\text { Matrix Metallopeptidases (MMP-9-like) }\end{array}$ \\
\hline & Serine peptidases & Oligopeptidases B Prolyl and endopeptidase Tc 80 \\
\hline & Treonine peptidases & Proteasome \\
\hline & Aspartic peptidases & Cruzipsin-I (CZP-I) and cruzipsin-II (CZP-II). \\
\hline \multirow{5}{*}{ Leishamania spp. } & Cysteine peptidases & $\begin{array}{c}\text { Cathepsin L-like CPA and CPB } \\
\text { Cathepsin B-like CPC } \\
\text { Calpains }\end{array}$ \\
\hline & Metallopeptidases & gp63 \\
\hline & Serine peptidases & $\begin{array}{l}56 \mathrm{kDa} \\
68 \mathrm{kDa} \\
110 \mathrm{kDa}\end{array}$ \\
\hline & Aspartic peptidases & Cathepsin D -like \\
\hline & Treonine peptidases & Proteasome \\
\hline \multirow{4}{*}{ African group } & Cysteine peptidases & $\begin{array}{c}\text { CP1 and CP2 (congopain or trypanopain- } \mathrm{Tc} \text { ) } \\
\text { Trypanopain- } \mathrm{Tb} \text { (or brucipain) } \\
\text { Rhodesain }\end{array}$ \\
\hline & Metallopeptidases & $\begin{array}{l}\text { TbMSP-A, } \\
\text { TbMSP -B and } \\
\text { TbMSP -C }\end{array}$ \\
\hline & Serine peptidases & Oligopeptidase B (OpdB), \\
\hline & Treonina peptidases & Proteasome \\
\hline \multirow[t]{2}{*}{ Lower trypanosomatids } & Cysteine peptidases & $\begin{array}{c}\text { 40-120 Kda } \\
\text { Calpains- like }\end{array}$ \\
\hline & Metallopeptidases & gp63-like \\
\hline
\end{tabular}


cruzipain has been characterized and is located in clan CA, family $\mathrm{C} 1$ (Fig. 1). Recently, the calpains of clan CA and family $\mathrm{C} 2$ have been studied in this parasite (Fig. 1).

Another cysteine peptidase found in T.cruzi is the metacaspase, which is also located in clan CD and belongs to the family C14, (Fig. 1). Clan CD enzymes differ fundamentally from those in clan $\mathrm{CA}$, which allows them to be readily distinguished. The catalytic cysteine-histidine $(\mathrm{CH})$ dyad is crucial to all cysteine peptidases for activity. For instance, the order of catalytic $\mathrm{CH}$ residues in protein differs in clan $\mathrm{CD}(\mathrm{HC})$ and $\mathrm{CA}(\mathrm{CH})$. The clan $\mathrm{CD}$ is not inhibited by $\mathrm{E}-$ 64, an archetypal and potent cysteine peptidase inhibitor. Whereas the catalytic dyad $\mathrm{CH}$ is sufficient for clan $\mathrm{CD}$; however, other cysteine peptidases possess an additional highly conserved amino acid that is involved in the catalytic mechanism. For instance, either an asparagine or aspartic acid residue is present in clan $\mathrm{CA}$, serving to orientate the active site histidine [57].

\section{Family C1 (Cruzipain and Others)}

Cruzipain also called gp57/51 and cruzain (the recombinant catalytic domain of cruzipain) is the major cysteine peptidase in $T$. cruzi and it is expressed as a complex mixture of isoforms. The enzyme is found in all developmental forms of different $T$. cruzi isolates, with levels 10-fold higher in epimastigotes and is active in the $\mathrm{pH}$ range of 5.0 to 7.5 [5860]. Cruzipain has an N-terminal catalytic domain linked to an antigenic C-terminal extension, the gp25 [61, 62]. Structural characterization of the oligosaccharide chains revealed the presence of sulfated residues that are essential for cruzipain recognition by $\mathrm{IgG}$ antibodies from the serum of chagasic patients $[63,64]$.

This peptidase is localized in different cell compartments, depending on the life cycle stage. The enzyme in the late endosome compartments of $T$. cruzi epimastigotes is called reservosome [65]. Meanwhile, in the intracellular amastigote, the principal stage for drug targeting, much of

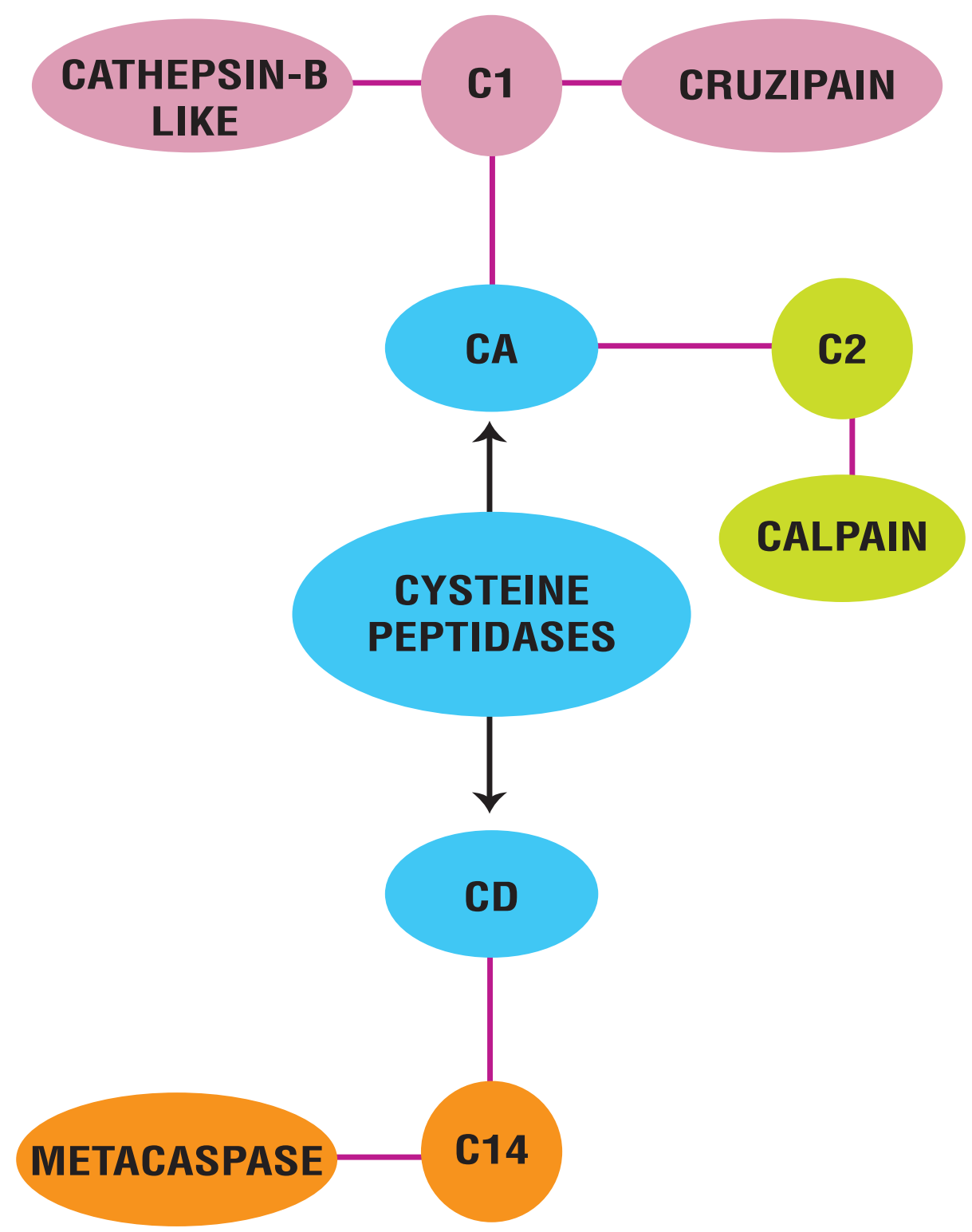

Fig. (1). Overview of representative enzymes in Trypanosoma cruzi that belong to cysteine peptidase families. 
cruzain is found on the surface of the parasite, directly in contact with host cell cytoplasm $[65,41]$.

Beyond its function in parasite nutrition as a lysosomal peptidase, the enzyme has been implicated in other cellular processes including cell invasion, proliferation, parasite differentiation and metacyclogenesis $[60,66]$. Selective inhibitors of this peptidase block the proliferation of both extracellular epimastigotes and intracellular amastigotes and arrest metacyclogenesis in vitro, indicating that the enzyme performs essential functions for parasite survival such as differentiation and growth [67-69].

Host peptidase inhibitors such as $\alpha$-2-macroglobulin $(\alpha-$ 2M) and kininogens interact with $T$. cruzi cruzipain in extravascular infection sites, linking inflammation to innate immunity by different mechanisms [70]. Cruzipain has the ability to generate kinin released from kininogens due to its activity of 'kininogenase' [71, 72]. Although soluble kininogens are not efficiently processed by cruzipain, the interactions of kininogens with sulfated glycosaminoglycans displayed at cell surface render the kinin-precursor molecules sensitive to proteolytic processing by cruzipain [73]. Once liberated, kinins bind to the bradykinin $\mathrm{B} 2$ receptor $\mathrm{B}_{2} \mathrm{R}$, which is expressed by a wide range of cell types, including cardiomyocytes, or promote the signaling of the inducible receptor $B_{1} R$ [74-76]. Chagasin, the endogenous cruzipain inhibitor, is a $T$. cruzi protein that also plays an important role in parasite differentiation and infectivity [77].

In recent years cruzipain had been studied as a drug target and several inhibitors are in development at experimental levels as well as by use of computer-assisted molecular design such as the classical two-dimensional quantitative structure-activity relationships (2D QSAR) and hologram QSAR (HQSAR) studies [52]. Currently, a cruzipain inhibitor, the vinyl sulfone K777 has entered in preclinical drug development investigations [41].

In addition to the cruzipain, all the $T$. cruzi life cycle forms express a cathepsin B-like cysteine peptidase with a molecular mass of $30 \mathrm{kDa}$, which may also be considered an immunogenic molecule, since antibodies against this peptidase were detected in chagasic patients as well as in patients with mucocutaneous leishmaniasis and kala-azar patients $[78,79]$.

A novel cysteine peptidase released to the culture medium during $T$. cruzi metacyclogenesis was described by Duschak et al. [80]. This proteolytic activity, named TcCPmet, has a molecular mass between 97 and $116 \mathrm{kDa}$, being active at pH 6.0 in SDS-PAGE. The enzyme was not recognized by anti-cruzipain antibody, suggesting a different nature of both cysteine peptidases. This new cysteine peptidase activity seems to be a feature of metacyclic trypomastigote and makes this finding more attractive by suggesting that it is developmentally regulated. This fact reinforces a possible role for this cysteine peptidase during metacyclogenesis. In addition, the authors also suggest the involvement of this enzyme in the protein degradation processes necessary for this stage-specific transformation [80].

\section{Family C2 (Calpains)}

Calpains (calcium-activated non-lysosomal peptidases, CAPN) are neutral peptidases that respond to $\mathrm{Ca}^{2+}$ signals by cleaving specific protein substrates, thereby irreversibly modifying their function [81]. Members of this peptidase family are present in a variety of organisms including trypanosomatids and are involved in diverse cellular processes including apoptosis, signal transduction, differentiation and cytoskeleton remodeling [82, 83]. They contain several calcium-binding sites, which affect allosterically the enzyme activity $[84,85]$.

Genome sequences of the Tritryps ( $T$. cruzi, T. brucei and Leishmania major) have recently become available: the cysteine peptidases in these species are a large family of peptidases that include calpain-like genes [86]. A gene encoding the T.cruzi calpain (CALP), TcCALPx11 (GeneDBID Tc00.1047053506563.210), was identified by microarray analysis as being differentially expressed by $T$. cruzi during metacyclogenesis. Its expression during nutritional stress preceding $T$. cruzi metacyclogenesis was 2.53 times higher than that observed in epimastigotes [83]. Antiserum against a recombinant TcCALPx11-GST-fusion protein reacted with a protein band at $80 \mathrm{kDa}$ in $T$. cruzi epimastigote protein extracts by western blot analysis, which corresponds to the estimated molecular mass of TcCALPx11 without posttranslational acylation, thereby confirming the prediction from in silico analysis $[83,86]$. Western blot with parasite extracts during metacyclogenesis showed an increase in the abundance of $T c$-CALPx11 in parasites under nutritional stress. Three types of stress (nutritional, temperature and acidic $\mathrm{pH}$ ) were tested and the TcCALPX11 expression increased irrespective of the type of stress applied to the parasite. TcCALPX11 was not detected during T. cruzi amastigogenesis [83]. T. cruzi calpain also presented a strong cross-reactivity with anti-Drosophila melanogaster calpain and anti-cytoskeleton-associated protein from T. brucei antibodies, and labelling was found mainly intracellularly. No significant cross-reactivity was found with anti-human brain calpain antibody. The expression of calpain was decreased in cells kept for long periods in axenic cultures in comparison to a strain recently isolated from mice. Different levels of calpain expression were also detected in distinct phylogenetic lineages, like Y strain (lineage TCII), Dm28c (TCI) and INPA6147 strain (Z3 zymodeme). Interestingly, the calpain inhibitor III (MDL28170) at $70 \mu \mathrm{M}$ promoted a strong reduction on the growth rate of $T$. cruzi Dm28c strain after 48 h [87].

\section{Family C14 (Metacaspases)}

Caspases are a conserved family of central effector cysteine peptidases involved in inflammatory disease, neurodegenerative disorders and apoptosis [88]. Recent works report the presence and functionality of metacaspases in $L$. major, T. brucei, and T. cruzi [89-93]. Five metacaspase genes (TbMCA1-TbMCA5) have been identified to date in $T$. brucei [89]. The genome of $T$. cruzi, contains two genes, TcMCA3 and TcMCA5, with homology to those encoding metacaspases, distantly related to the caspases involved in programmed cell death (PCD) in higher eukaryotes. TcMCA3 is present in the CL Brener clone at 16 copies per haploid genome, arrayed in two tandems located in chromosomes of 0.54 and $0.98 \mathrm{Mbp}$. TcMCA5, on the other hand, is present as a single copy gene $[91,94]$. The proteins encoded were expressed in Escherichia coli BL21 (DE3) cells, to 
generate antibodies, which showed that TcMCA3 is expressed in the four major stages of the parasite, whereas TcMCA5 is expressed only in the epimastigote form. Moreover, recombinant TcMCA3, but not TcMCA5, was recognized in most sera from chronic chagasic patients, showing that the protein is expressed during natural infections [91]. Using synthetic caspase substrates, Jimenez et al. [95] detected an increase in caspase-like activity in epimastigotes at the stationary phase of growth, indicating that these enzymes may be involved in some of the apoptotic features.

\section{gp63 and other Metallopeptidases}

In $T$. cruzi several types of metallopeptidases have been described, some of them specifically expressed during metacyclogenesis in various strains and clones of $T$. cruzi [96, 97]. In addition, multiple isoforms of the endopeptidase gp63 (clan MA, family M8) family have been found as well as matrix metallopeptidases-like peptidases [98, 99]. Recently, exopeptidases such as metallocarboxypeptidases were found in the cytoplasm of the parasite $[100,101]$.

\section{gp63}

T. cruzi expresses multiple isoforms of the gp63 family of metallopeptidases at all life stages [98]. A polyclonal antiserum against recombinant gp63 of $T$. cruzi (Tcgp63) was used as a tool in order to study Tcgp63 expression and localization in this parasite. By Western blot analysis, biotinylation, endoglycosidase digestion and immunofluorescence, Tcgp63 was detected as a surface glycoprotein with a molecular mass of $61 \mathrm{kDa}$ in epimastigotes and as a non $\mathrm{N}$ glycosylated and intracellular protein with a molecular mass of $55 \mathrm{kDa}$ in metacyclic trypomastigotes. Amastigote presented a molecular mass of $61 \mathrm{kDa}$ [102]. Moreover, preincubation of trypomastigotes with either Tcgp63 antiserum or a purified Tcgp63 C-terminal subfragment reduced infection of host myoblasts suggesting that isoforms play a role in host cell infection

\section{Metallocarboxypeptidases}

Two cytosolic metallocarboxypeptidases of the M32 family, isolated from $T$. cruzi CL Brener clone, have recently been characterized: $T c M C P-1$ and TcMCP-2 [100]. Both of them showed to be closely related in sequence $(67 \%)$ by displaying temporary expression patterns and substrate preferences. These peptidases differ in their pattern of expression: while $T c \mathrm{MCP}-1$ is present in all life stages of $T$. cruzi, TcMCP-2 is mainly restricted to the stages that occur in the invertebrate host. TcMCP-1 removes basic C-terminal residues, whereas TcMCP-2 prefers hydrophobic/aromatic residues. The structure of TcMCP-1 shows strong topological similarity with archaeal, bacterial and mammalian metallopeptidases including the angiotensin-converting enzyme, neurolysin and thimet oligopeptidase. These enzymes, like other T. cruzi peptidases, could be a potential target in Chagas' disease at the molecular level and provide a template for the design of novel therapeutic approaches [100, 101].

\section{Matrix Metallopeptidases}

Matrix metallopeptidases (MMPs) are a family of structurally related zinc-dependent peptidases that are able to hydrolyze the major components of the extracellular matrix (ECM), such as collagen, elastin, fibronectin and laminin
[103]. Thereby, these enzymes play a central role in processes that involve ECM remodeling, including embryonic development, bone remodeling, invasive processes such as angiogenesis, tumor metastasis and tissue repair [104, 105]. Moreover, MMPs help mediate inflammatory cell migration because they can degrade all components of the ECM, clearing the path for migrating cells of the immune and repair responses [106]. MMPs have distinct but overlapping substrate specificities, and apart from the extracellular matrix, MMPs may cleave a wide range of non-matrix substrates, such as pro-forms of other MMPs, cell-adhesion molecules, chemokines, cytokines, growth factors, their receptors, and junctional proteins, either to augment or to inhibit the functional activity of these substrates [107].

Increased levels of various MMPs (collagenases, stromelysins, and gelatinases) have been associated with inflammatory diseases of connective tissues. The actions of the collagenases MMP-2 and MMP-9 are involved in regulation of the inflammatory response in several circumstances, including the direct cleavage of immune system proteins. In the acute phase of $T$. cruzi infection, myocardial inflammatory infiltrate produces a significant tissue injury, which may cause acute morbidity and mortality. This inflammation is modulated by cytokines and chemokines produced by leukocytes and cardiomyocyte during $T$. cruzi infection [108, 109]. Gutierrez et al. [110] investigated the role of MMP-2 and MMP-9 in the myocarditis induced by $T$. cruzi, using immunohistochemical, zymography with gelatin as substrate and enzyme-linked immunosorbent assays as well as realtime polymerase chain reaction as methodologies. Mice treated with the MMP inhibitor doxycycline, showed a decrease of heart inflammation, delayed peak in parasitemia and improved survival rates when compared with the control group. Reduced levels of cardiac tumor necrosis factor- $\alpha$, interferon- $\gamma$, and serum nitrate were also observed in the treated group. These results show that MMPs play a role in Chagas myocarditis. An involvement of MMPs were also observed for viral myocarditis with high levels of MMP-9, MMP-2 and MMP-12 [106]. In addition, peptidasedependent extracellular matrix remodeling is one of the events that it is emerging as a key regulator of $T$. cruzi infection and pathogenesis of Chagas' disease. In this sense, earlier studies from our group showed MMP-9-like activity in the cytoplasm of $T$. cruzi during in vitro infection of embryonic hepatocyte cells [99].

\section{Serine Peptidase}

Serine peptidases described in $T$. cruzi include two peptidases of the prolyl oligopeptidase family (clan SC, family S9): (i) Oligopeptidase $\mathrm{B}$, involved in $\mathrm{Ca}^{2+}$-signalling during mammalian cell invasion and (ii) a prolyl endopeptidase Tc80 (POP Tc80).

\section{Oligopeptidases B (Tc OP or T. cruzi OpdB)}

Oligopeptidases B is a cytosolic enzyme with a molecular mass of $120 \mathrm{kDa}$, and belongs to the prolyl oligopeptidase family of serine peptidases. Oligopeptidases only hydrolyze peptides smaller than 30 amino acid residues and as a result have no naturally occurring inhibitors. It was proposed that the $\mathrm{Ca}^{2+}$ agonist generated by oligopeptidase $\mathrm{B}$ is exported from the parasite and binds to a receptor on the 
surface of cells, activating phospholipase $\mathrm{C}$ and generating inositol phosphate, which binds to its receptor on the membrane of endoplasmic reticulum and promotes $\mathrm{Ca}^{2+}$ release [111-113]. Oligopeptidase B null mutant trypomastigotes are defective in mobilizing $\mathrm{Ca}^{2+}$ from thapsigargin-sensitive stores in mammalian cells and in establishing infection in vitro and in vivo [113]. The enzyme is directly involved with the parasite ability to invade a wide variety of mammalian cells and consequently in the establishment of the infection [52, 111-113]. This enzymatic activity could also be associated with Chagas' disease pathogenesis by hydrolyzing host proteins and inducing host immune responses [114].

\section{Prolyl Endopeptidase Tc 80 (POP Tc80)}

This enzyme has been identified in cell-free extracts of $T$. cruzi trypomastigotes, amastigotes and epimastigotes. This peptidase mediates the specific degradation of purified human types I and IV collagens and fibronectin. Thus, the enzyme may facilitate $T$. cruzi migration through the extracellular matrix, gaining access to cells in virtually any part of the host body, or may be involved in the host cell invasion, cleaving collagen and interacting with integrin receptors [115-117].

\section{Proteasome}

Protein modification by ubiquitin and ubiquitin-like proteins is one of the most complex and intensely studied mechanisms of post-translational protein regulation in eukaryotes. Conjugation of the 76-amino-acid protein ubiquitin is first and foremost a signal for targeting proteins to the proteasome for degradation, but there is evidence that ubiquitin also plays diverse roles in the regulation of numerous biological pathways [118]. Two research groups first identified ubiquitin genes in T. cruzi nearly two decades ago [119, $120]$. Later, the presence of the $26 \mathrm{~S}$ proteasome and the ubiquitin pathway in $T$. cruzi were reported for the first time by de Diego et al. [121]. The 26S proteasome of T. cruzi epimastigotes was identified as a high molecular mass complex $(1400 \mathrm{kDa})$ with an ATP-dependent chymotrypsin-like activity against the substrate Suc-LLVY-Amc (Succinyl LeuLeu-Val-Tyr-7-amino-4- methylcoumarin).

Experiments with specific inhibitors of proteasome activity such as peptide aldehydes (e.g. N-Acetyl-Leu-LeuLeucinal, MG132), lactacystin and gliotoxin have helped to define the role of the proteasome in various parasitic protozoa processes, including replication and differentiation [122]. Lactacystin treatment in $T$. cruzi inhibits both the transformation of trypomastigotes to amastigotes and the development of amastigotes into trypomastigotes, thus implicating proteasomes in parasite remodeling [123]. Moreover, lactacystin treatment promotes the conjugation of ubiquitin to flagellar proteins and the accumulation of ubiquitinated products during transformation [121]. Recently, Cardoso et al. [124] found that epimastigotes treated with lactacystin were still able to adhere to the substrate, but did not differentiate into metacyclic trypomastigotes. In addition, lactacystin treatment blocked epimastigote multiplication, since flow cytometry data demonstrated that $T$. cruzi epimastigotes cultured in lactacystin-containing LIT medium were arrested at the G2 phase of the cell cycle. These findings suggest that proteasomes are involved in $T$. cruzi cell growth and metacyclogenesis in vitro.

Antigenic peptides derived from intracellular proteins are continuously presented to the immune system by MHC class I molecules on the surface of immune and non-immune cells and the major proteolytic system generating peptide ligands are dependent on proteasomes [125]. The 20S proteasome is the key peptidase generating peptides for the MHC class I antigen presentation pathway. In this sense, some studies have been done in order to ask whether in vitro $T$. cruzi infection might influence the gene expression or protein profile of the 20S proteasome. This could be the explanation for the chronic phase of the Chagas' disease in the same way that certain viruses have developed strategies to evade class Irestricted antigen processing and presentation [126]. When Faria et al. [127] compared T. cruzi-infected HeLa cells with non-infected cells, no differences between the composition of $20 \mathrm{~S}$ proteasome and expression of its subunits were observed. This included the interferon- $\gamma$ inducible subunits and failed to induce the formation of immunoproteasome. However, the proteasome trypsin- and chymotrypsin-like activities were higher in infected cells than in non-infected cells.

Recently, three monoclonal antibodies were produced against $T$. cruzi proteasomes (7E5, 25A10 and 18F7) and all of them reacted with a single band of $27 \mathrm{kDa}$ on immunoblots of purified proteasomes. Using the 7E5 antibody which recognizes the $\alpha$-subunit of protozoan peptidase, $T$. cruzi $20 \mathrm{~S}$ proteasomes were found not only in the cytoplasm and nucleus but also in the kinetoplast [128]. The proteasome $20 \mathrm{~S}$ was present in all $T$. cruzi stages in similar amounts. These results point to a possible role of the ubiquitin proteasome system in the kinetoplast biochemistry. This multicatalytic system could be involved in different biological functions such as the cell cycle in the replicative stages of T.cruzi or remodeling in trypomastigotes that do not divide. However, further studies need to be carried out to establish the complete function of this structure on T. cruzi biology [128].

\section{Aspartic Peptidases}

Recently, two aspartic peptidases were isolated from $T$. cruzi epimastigotes, named cruzipsin-I (CZP-I) and cruzipsin-II (CZP-II). Cruzipsin-II was isolated from a soluble fraction and the other was solubilized with 3-[(3cholamidopropyl-dimethylammonio]-1-propanesulfonate

(CHAPS) [129]. Both peptidase activities were inhibited by the classic inhibitor pepstatin $\mathrm{A}$ and the aspartic active site labeling agent 1,2-epoxy-3-[phenyl-nitrophenoxy] propane (EPNP). Although the genome of $T$. cruzi has been already decoded, no pepsin-like peptidase has been detected [94]. However, the authors explain that probably several sequences could not be correctly identified because of the great difficulty to correlate homologous genes by using the current computer techniques.

\section{PEPTIDASES IN LEISHMANIA SPP.}

\section{Cysteine Peptidases}

In parasitic protozoa, cysteine peptidases are particularly important for Leishmania survival, replication, development, metabolism, host cell infection and evasion of the host immune response. Thus, they have attracted considerable inter- 
est as targets for the design of new chemotherapeutic agents and vaccines [57]. Leishmania spp. contain three types of clan CA cysteine peptidases the cathepsin L-like CPA and $\mathrm{CPB}$ and the cathepsin B-like CPC [57]. These CPs are frequently referred to as the only CPs in Leishmania. However, a detailed analysis on the database of the $L$. (L.) major genome reveals a total of 56 genes that codify for hypothetical CPs, which are divided into 4 clans and 13 families. It is possible that these CPs play crucial roles for the parasite, although until now the role of most of these CPs can only be predicted, based on the current knowledge of homologous enzymes [57].

So far, functionally well characterized cysteine peptidases are from the New World species of the Leishmania mexicana group. In this complex, the $c p b$ genes are multicopy and are located in a single locus of 19 copies arranged in a tandem repeat $[130,131]$. The first two copies of CPB, $\mathrm{CPB} 1$ and $\mathrm{CPB} 2$, are expressed in the infective metacyclic promastigote stage of the parasite, while the others are expressed predominantly in the intracellular amastigote stage [130-132]. Information about the roles and importance of the enzymes in host-parasite interactions was obtained by the generation of a $L$. (L.) mexicana CPB-deficient $(\Delta c p b) \mathrm{mu}-$ tant. It was shown that $\Delta c p b$ promastigotes are less infective to macrophages than wild-type parasites in vitro and that $\Delta c p b$ promastigotes and amastigotes are able to form only small, slow-growing lesions in BALB/c mice $[130,133$, 134]. Curiously, only marginal recovery of lesion growth, at best, could be restored to $\Delta c p b$ mutants by reinserting individual CPB genes on episomes [130, 134]. However, the reinsertion of multiple $\mathrm{CPB}$ genes in these $\Delta c p b$ mutants was able to effectively restore virulence [135]. Therefore, the level of CPB expression or the diversity in CPB isoenzymes or both are important for parasite virulence, which provides an explanation for the presence in L. mexicana of a multicopy tandem array of CPB genes [135]. Also shown was that the absence of the $c p b$ genes resulted in a shift in the immune response from predominantly Th2 immune response (wild-type) to the Th1 response, normally observed when the CPB isoenzymes are present [133]. It has also been suggested that in L. mexicana these enzymes are vital for autophagy and differentiation of the parasite [136]. Recently, our group described that drug-induced Leishmania autophagy is accompanied by enhanced cpb expression [137].

The members of the $L$. (L.) donovani complex also possess multiple classes of cysteine peptidases, which are developmentally regulated $[138,139]$ and are involved in intracellular parasite survival [140]. Furthermore, it was proposed that $L$. donovani and $L$. chagasi cysteine peptidases activate the kinin system, a group of potent vasoactive peptides proteolytically liberated from kininogens, which have been recognized as signals alerting the innate immune system [141].

In despite of the substantial advance in knowledge of the cysteine peptidases from the L. mexicana complex and to a lesser degree in the $L$. donovani complex, less is known about the L. braziliensis. The genome annotation is in progress and the major CPs gene groups have already been identified. However, there are limited reports on the occurrence of $\mathrm{CP}$ activities in this parasite. So far, only cysteine pepti- dases ranging from $20 \mathrm{kDa}$ to $65 \mathrm{kDa}$ have been reported in L. braziliensis [142].

A polyclonal antibody to L. amazonensis CPB was able to recognize polypeptides in L. braziliensis $[143,144]$ and its expression seems to be correlated to parasite virulence [144]. A $c p b$ gene from L. (V.) braziliensis was cloned and expressed, revealing differences in substrate utilization between L. mexicana and L. braziliensis CPs [145]. Curiously, although several reports have related parasite virulence to the expression of key virulence factors, a recent report indicated that the lizard non-pathogenic to humans L. tarentoale expresses an amastin-like, CPB, lipophosphoglycan (LPG) and gp63 molecules at comparable levels to those in L. major and L. infantum, both at the mRNA and protein levels [146]. Indeed, the "non-pathogenic to humans" concept needs to be revisited in the light that reports of leishmaniasis-like diseases caused by presumed monoxenous trypanosomatids have been increasing drastically in recent years [31, 147].

Calpains, as cited in the topic T. cruzi peptidases, were detected in Leishamnia spp.. In L. major, a total of 27 calpain-like proteins have been described based on a genome search for conserved domains [148]. As yet there are no data on the specific functions for any of the calpain-like proteins in Leishmania. In L. major, it was demonstrated that a calpain related protein (LmCALP20.2) is up regulated in the promastigote insect stage and LmCALP20.1, coded by the adjacent gene, is up regulated in the subsequent metacyclic insect stage [149]. Our group demonstrated that MDL28170, a potent calpain inhibitor, is capable of reducing promastigote growth in culture and induces cell death [150], probable through apoptosis (unpublished data). A proteomics screen implicated a calpain-related protein in drug resistance in $L$. donovani clinical field isolates, probably by modulating drug-induced apoptosis [151]. Highly sensitive gene expression microarray analysis revealed that calpains, among other genes, are differentially expressed in Leishmania parasites isolated from post kala-azar dermal leishmaniasis (PKDL) patients in comparison with those from visceral leishmaniasis (VL) [152]. A calcium-activated peptidase in the cytosolic fraction of $L$. donovani has been found to digest different endogenous proteins when subjected to SDS-PAGE. Gelatin-embedded gel electrophoresis confirms the presence of calcium-dependent peptidase [153]. However, there is no protein sequence linking this activity to a calpain and the absence of amino acid residues essential for catalytic activity and the moderate overall degree of sequence identity of calpains genes suggest that most calpain-like proteins do not act as cysteine peptidases [148].

\section{Metallopeptidases}

Leishmanolysin, promastigote surface protease (PSP), major surface protease (MSP), EC 3.4.24.36 or gp63 are the designations for the most abundant surface glycoprotein of Leishmania spp. [154], which is distributed over the entire surface of the promastigote forms, including the flagellum [155-157]. Each L. major promastigote in the stationary phase is estimated to have 500,000 copies of gp63, constituting about $1 \%$ of the organism's total protein content [158]. Experiments using surface biotinylation, cytofluorimetry and immunoelectron microscopy showed that three-quarters of $L$. mexicana gp63 occur on the cell surface, whereas the re- 
mainder is located intracellularly [158]. Moreover, gp63 is also released by promastigotes to the extracellular medium in both membrane-associated and free forms [155, 159]. Although the GPI anchor can be cleaved in vitro with phospholipase $C$ (PLC) revealing the cross-reacting determinant (CRD) epitope, evidence using antibody against CRD indicates the GPI anchor is not enzymatically cleaved in vivo during the release from the Leishmania cell $[160,161]$. The release of L. amazonensis gp63 into the extracellular environment has been shown to be powerfully reduced either in the presence of a metal chelator 1,10-phenanthroline, or in the case of gp63 mutation at the active site. This suggests that gp63 release is dependent on autoproteolysis [160].

All gp63 studied to date in the different Leishmania species share high nucleotide sequence identity and the enzyme has been shown to be encoded by a family of tandemly linked genes, all of which map to a single chromosome [162, 163]. Additionally, the crystal structure of gp63 purified from $L$. major promastigotes reveals that this peptidase is a member of the metzincin family of zinc metallopeptidases, with an active site sequence motif of HEXXHXXGXH [164]. Structural studies indicate that the gp63 likely exists as homodimers and both amphiphilic and hydrophilic forms have been found in the same cell [165]. As described above, several Leishmania spp. contain distinct classes of gp63 genes that are developmentally regulated in different parasite life cycle stages, including the amastigote, logarithmic promastigote and metacyclic promastigote forms [166]. Consequently, gp63 plays vital roles in the different stages of the Leishmania life cycle.

Also gp63 presents wide substrate utilization, including extracellular matrix components such as type IV collagen and fibronectin, which could facilitate the migration through the sub-endothelial basement membrane, facilitating the dissemination of the parasite in the tissues [167]. On the other hand, the in vivo substrates of gp63 are unknown. Several possible additional roles were suggested for the gp63 molecule when the promastigote is inside the mammalian host: (i) it helps promastigote evasion of complement-mediated lysis, by cleaving C3 to its breakdown products [168] as well as converting $\mathrm{C} 3 \mathrm{~b}$ to the inactive form $\mathrm{iC} 3 \mathrm{~b}$ [169], (ii) it enhances phagocytosis of promastigotes through macrophage receptors such as CR3 [169-171], (iii) it contains the sequence SRYD that is antigenically related to the RGDS sequence of fibronectin, suggesting a potential interaction of gp63 with macrophage fibronectin receptors [172], (iv) it promotes degradation of host cytosolic MARCKS-related protein [173], (v) it is capable of cleaving surface CD4 and could diminish $\mathrm{T}$ cell responses [174] and (vi) it also cleaves intracellular peptides presented by MHC class I molecules [175].

The relevance of gp63 molecules on the interaction with the invertebrate host has been the subject of recent publications. Gp63 is predominantly present on the surface of promastigotes, which reside in the midgut of the phlebotomine sandfly vector $[176,177]$. However, L. major gp63 knockout presented a similar number of metacyclic promastigotes in the anterior gut of Phlebotomus dubosqui [178]. On the other hand, the down-regulation of gp63 in L. amazonensis affected considerably the parasite development in Lutzomyia longipalpis [179]. Our group has demonstrated that leishmanolysin-like proteins from insect and phytoflagellate trypanosomatids can function as adhesive molecules, promoting the connection of live parasites to the invertebrate host epithelial cells [15]. Indeed, an insect receptor able to bind purified gp63 has been identified [29].

Although there are no records about MMPs in Leishmania spp., Costa and co-workers et al. [180] observed the presence of MMP-9-like activity in L. chagasihepatocyte-macrophage co-culture supernatants, where the higher MMP-9 activity coincided with an increase in TGF- $\beta$ production which took place when macrophage leishmanicidal activity was the highest. This fact suggests that this cytokine could be participating in metallopeptidase activation/conversion and probably in matrix deposition by hepatocytes in culture.

\section{Serine Peptidases}

The first experimental evidence of serine peptidases in Leishmania spp. was demonstrated in 2000 by AlmeidaCampos and Horta [181]. The authors correlated the lytic effects of crude extracts of L. amazonensis to macrophages due to a serine peptidase, based on the inactivation of this effect by specific inhibitors. A serine peptidase-like triad was later identified in L. major, the enzyme hydrolyzed benzoyl-Arg-p-nitroanilide, an activity sensitive to specific serine peptidase inhibitors [182]. In L. amazonensis, subcellular localization studies by immunoelectron microscopy suggested that a promastigote serine peptidase of approximately $56 \mathrm{kDa}$ is predominantly located in the flagellar pocket and in vesicular structures that are morphologically similar to the compartments of mammalian endocytic as well as exocytic pathways. In amastigotes, the enzyme was found to be located in electron dense structures corresponding to megasomes in addition to subcellular structures like flagellar pocket and cytoplasmic vesicles, as seen in promastigotes [183]. An additional $68 \mathrm{kDa}$ [184] enzyme was identified and seems to be present at the cell surface, as well as in cytoplasmic membranous compartments of the parasite [185]. In addition, a $110 \mathrm{kDa}$ serine peptidase that occurs in the detergent-soluble extract of this parasite seems to be a dimer of 60 and $45 \mathrm{kDa}$ [186]. A released enzyme of $110 \mathrm{kDa}$ was also identified and seems to occur as a homodimer [187]. Similar enzymes were also identified in L. braziliensis [188] and L. donovani [189]. A common feature of these enzymes seems to be their ability to digest a wide range of proteinaceous substrates and several enzymes are homodimeric or heterodimeric proteins. As yet, no specific functions have been addressed to these enzymes. The toxic effects of classical serine peptidase inhibitors on L. amazonensis parasites were correlated to enzymatic inhibition [190].

\section{Aspartic Peptidases}

The activity of aspartic peptidases was first demonstrated in 2005 [191]. Alves and co-workers showed that metallo, serine and aspartic peptidase activities are down-regulated during the shock-induced transformation of promastigotes into amastigotes, by the hydrolysis of specific chromogenic substrates. Later, Valdivieso et al. [192] reported the presence of an enzyme capable of degrading the synthetic substrate benzoyl-Arg-Gly-Phe-Phe-Leu-4-methoxy- $\beta$-naphthyl- 
amide, which is selective for cathepsin D like aspartic peptidases. Diazo-acetyl-norleucinemethylester (DAN) not only inhibited the enzyme activity but also interfered in parasite growth in culture. The dramatically increasing numbers of patients co-infected with Leishmania and HIV [193], together with data from fungal infections showing that the inhibitors of HIV aspartic peptidases (HIV-PIs) have a direct effect on opportunistic pathogens [194] instigated researchers to seek for direct effects of HIV-PIs on Leishmania. In this context, Savoia and co-workers in 2005 [195] first demonstrated the dramatic effects of indinavir and saquinavir on the growth of L. major and L. infantum. Later, it was demonstrated that HIV-PIs powerfully reduce $L$. infantum infection in macrophages, either co-infected or not with HIV [196]. Our research group demonstrated that the hydrolysis of a HIV peptidase substrate by L. amazonensis extract was inhibited by pepstatin A and several HIV-PIs, suggesting that an aspartic peptidase may be the intracellular target of the inhibitors [137]. In addition, HIV-PIs also impaired L. amazonensis growth and interaction with macrophages, indicating that the HIV-PIs are active against a wide range of Leishmania species. Also, the HIV-PIs induced several critical ultrastructural alterations in L. amazonensis promastigotes, which culminated with parasite death, probably through an imbalance between apoptosis and autophagy [137]. Despite all these beneficial effects, the HIV-PIs induced an increase in the expression of cpb and gp63, two well-known virulence factors expressed by Leishmania spp. [137]. The anti-proliferative effect of aspartic peptidase inhibitors makes this enzymatic class a putative new target for the development of leishmanicidal drugs. In addition, in the face of the leishmaniasis/HIV overlap, it is critical to further comprehend the sophisticated interplays among Leishmania, HIV and macrophages. In addition, there are many unresolved questions related to the management of Leishmania-HIVcoinfected patients. For instance, the efficacy of therapy aimed at controlling each pathogen in coinfected individuals remains largely undefined

\section{Proteasome}

Earlier studies have demonstrated the presence of proteasome in several species of the Leishmania genus [52]. The $L$. mexicana $20 \mathrm{~S}$ proteasome has a molecular mass of around $670 \mathrm{kDa}$, which is consistent with the size of $20 \mathrm{~S}$ proteasomes from other species [197], and it is composed of at least 10 distinct subunits in the 22 to $32 \mathrm{kDa}$ size range. However, the molecular mass of the L. mexicana proteasome increases to $1200 \mathrm{kDa}$ in the presence of ATP, consistent with there being a $26 \mathrm{~S}$ proteasome in the parasite, extending, thus, the range of eukaryotic species known to have the $26 \mathrm{~S}$ form of the proteasome. However, this proteasome has a substrate preference profile more similar to proteasomes from higher eukaryotes than from the related protozoan $T$. brucei, which has an unusually high chymotryptic peptidase activity [198]. On the other hand, the purified L. chagasi $20 \mathrm{~S}$ proteasome possesses proteins with molecular masses of 22$35 \mathrm{kDa}$ and exhibits a higher trypsin-like activity compared to chymotrypsin-like activity, as previously reported by Hua and colleagues for T. brucei [198].

Similar to what has been observed in $T$. cruzi, studies with specific inhibitors of proteasome activity have also helped to define the role of the proteasome in the Leishmania genus. For instance, lactacystin and its active form clastolactacystin b-lactone blocked the in vitro growth and intracellular survival of $L$. chagasi promastigotes and arrested the intracellular development of the lactacystin-treated parasites during the infectivity of $L$. chagasi promastigotes in mouse peritoneal macrophages [199]. The involvement of the proteasome in the regulation of $L$. mexicana cell cycle progression was demonstrated by the addition of a peptide aldehydes inhibitor (MG132), since this drug caused an accumulation of promastigotes with 4 n DNA content. This fact suggests that proteasome is required after DNA synthesis and before completion of mitosis, such that in conditions in which the proteasome is inactivated, parasite growth is arrested at this particular point of the cell cycle [200].

\section{PEPTIDASES IN AFRICAN TRYPANOSOMES}

\section{Cysteine Peptidases}

The major proteolytic activities in African trypanosomes result from cysteine peptidases, whose orthologs are found in all the species analyzed and collectively named trypanopains [201-203]. These enzymes share structural and functional similarities with $T$. cruzi cruzipain [203-206].

T. congolense possesses at least two families of CPs, named CP1 and CP2, the latter also known as congopain or trypanopain-Tc [207], while the enzymes in $T$. b. bruce $i$ and $T$. b. rhodesiense are termed trypanopain- $\mathrm{Tb}$ (or brucipain) and rhodesain, respectively [204, 205].

Congopain is a lysosomal enzyme that was purified from bloodstream forms [208], but it differs from mammalian cathepsins $\mathrm{B}$ and $\mathrm{L}$ by its broad $\mathrm{pH}$ activity profile and its high stability at neutral $\mathrm{pH}$, together with the presence of a C-terminal extension [209]. Congopain is a dominant antigen of trypanosomes, eliciting both humoral and cellular responses in cattle [206] and antibody-mediated inhibition of trypanosomal CPs may contribute to mechanisms of trypanotolerance [210]. Detection of procongopain and trypanosomal enzymatic activity in the plasma of $T$. congolense-infected cattle suggests that the enzyme may interact with host proteins during infection, such as to reduce the proliferation of bovine peripheral blood mononuclear cells in response to mitogens and antigens, as well as to interact with bovine kininogens to trigger the release of kinins [206]. It is also known that $\alpha$-2-macroglobulin effectively inhibits cysteine peptidase activity in African trypanosomes [204]. These data, together with the capacity of procongopain to be activated at a weakly basic $\mathrm{pH}$, suggest that procongopain may be extracellularly processed in the presence of blood vessel glycosaminoglycans, supporting the hypothesis that the enzyme acts as a pathogenic factor in the interaction of the parasite with its host [211].

Brucipain has also been shown to form active complexes with kininogen, and these circulating complexes may confer some advantage to the parasite by modulating host physiology or the immune response [212]. Brucipain and rhodesain are also located in the lysosome, mainly in $T$. $b$. rhodesiense in long slender forms and in T. b. brucei in short stumpy forms [205]. These activities are considered targets for chemotherapy and inhibitors of these peptidases were shown to kill the parasites both in culture and in experimentally 
infected animals, the killing being correlated with inhibition of trypanopains [205, 213]. The investigation into the roles of the endogenous inhibitor of cysteine peptidase (ICP) revealed that ICP acts as a regulator of brucipain activity, playing an important role in the modulation of surface coat exchange during differentiation, intracellular proteolysis and parasite infectivity to mice [214]. It was also demonstrated that brucipain plays an important role in the bloodstream forms of T. b. gambiense transendothelial migration of the human blood-brain barrier, which is correlated to the ability to evoke calcium fluxes in brain microvascular endothelial cells [215].

T. brucei also possesses a cathepsin B-like peptidase that is mainly located inside the endosomal vesicles, although it is actively found in the form of a circulating antigen as well [201, 216].

\section{Metallopeptidases}

Besides cysteine peptidases, another class of proteolytic enzymes found in African trypanosomes corresponds to homologues of Leishmania spp. major surface protease (MSP) [217]. T. brucei has three classes of MSP genes, called TbMSP-A, -B and -C that are differentially expressed during the parasite life cycle. In addition, TbMSP-B protein is a surface-located metallopeptidase that plays a role in the release of the variant surface glycoprotein (VSG) during differentiation from bloodstream forms to procyclic trypanosomes, being constitutively expressed in the latter [218].

\section{Serine Peptidases}

African trypanosomes also contain a serine oligopeptidase, oligopeptidase B $(\mathrm{OpdB})$, which is implicated in the pathogenesis of these parasites, since it is released into the bloodstream of infected mammalian hosts [219-221], where it retains its catalytic activity and may participate in the anomalous degradation of host peptide hormones [222]. In this sense, oligopeptidases B display similar properties to several hormone-processing enzymes, thus host-peptide hormones are candidates for cleavage by the parasite oligopeptidases [222]. In fact, the enzyme has been identified as a target of several trypanocidal drugs, such as suramin [223] and its proper characterization may lead to the design of highly selective inhibitors to be employed as trypanocidal drugs [222].

\section{Proteasome}

The first proteasome to be purified and characterized from a parasite was $T$. brucei proteasome and several differences between $T$. brucei and mammalian proteasomes have been found, such as their molecular mass (the 20S proteasome has a molecular mass of $630 \mathrm{kDa}$ in trypanosomes compared with $700 \mathrm{kDa}$ in mammals), and substrate specificity (T. brucei proteasome exhibits high trypsin-like but lower chymotrypsin-like activities compared with the mammalian counterparts) [52]. Nevertheless, the evidence of $26 \mathrm{~S}$ proteasome from $T$. brucei demonstrated that the absence of degradation of mammalian ornithine decarboxylaseantienzyme complex, which catalyzes the first step in the polyamine biosynthetic pathway, is the real difference between mammalian and trypanosomal 26S proteasome [224].
Preceding studies reported that lactacystin inhibited the proliferation of both the mammalian and the insect forms of T. bruce $i$ and arrest them in the G2/M and G1/S phases, respectively [200]. Two of five peptide trileucine methyl vinyl sulphones tested, containing different substituents at the $\mathrm{N}$ terminus (or $\mathrm{P} 4$ position) showed trypanocidal activities in vitro using culture-adapted bloodstream forms of $T$. brucei, since they inhibited trypsin-like activity [122, 225]. This may be attributed to the high and the low chymotrypsin-like activity of the trypanosomal proteasome, while the opposite is the case with the mammalian proteasome [198]. Therefore, proteasome inhibitors specifically targeting the proteasomal trypsin-like activity may be the rational choice for future anti-sleeping sickness drug development.

\section{PEPTIDASES IN LOWER TRYPANOSOMATIDS}

Up to now, the proteolytic activities extensively described in lower trypanosomatids belong to the metallo and cysteine peptidase classes [5, 14, 18, 226]. In this context, peptidases with similar biochemical and/or immunological properties to the gp63 [165] and cruzipain [227] were identified in different species of Herpetomonas (H. samuelpessoai, $H$. roitmani, $H$. anglusteri and $H$. megaseliae), Leptomonas (L. samueli, L. seymouri, L. collosoma and L. wallacei) Crithidia (C. fasciculata, $C$. guilhermei and $C$. deanei), Blastocrithidia (B. culicis) and Phytomonas ( $P$. serpens and P. françai) [6-18, 20-26, 28-30, 154, 228-232].

\section{Cysteine Peptidases}

Lower trypanosomatids also produce cysteine peptidase activities, whose expression is dependent of growth conditions, like culture medium and time of incubation. However, all the cysteine peptidases are active at acidic $\mathrm{pH}$ and completely restrained by E-64, a powerful cysteine peptidase inhibitor. In addition, the cysteine peptidases produced by these flagellates were exclusively detected in the parasite cellular extracts, except for $C$. desouzai, $C$. deanei [23] and $P$. serpens $[16,20]$, whose cysteine peptidase activities were also characterized in the extracellular medium. At least in $P$. serpens, both cellular and extracellular cysteine peptidases were able to degrade several proteinaceous substrates, suggesting a possible participation of these enzymes in parasite nutrition [16, 20]. Moreover, a $40 \mathrm{kDa}$ cysteine peptidase synthesized by $P$. serpens cells cleaved a $115 \mathrm{kDa}$ surface polypeptide located at the surface of a salivary gland from Oncopeltus fasciatus, a phytophagous insect, implicating a possible participation of this cysteine peptidase in interaction processes [20]. Corroborating the preceding statement, cysteine peptidase inhibitors were capable of blocking the adhesion process between $P$. serpens promastigote cells and salivary glands of $O$. fasciatus [16]. In H. samuelpessoai, a 45 $\mathrm{kDa}$ cysteine-type peptidase was down-modulated during the cellular differentiation triggered by both temperature switch and dimethylsulfoxide treatment $[13,232]$. Cysteine peptidase production was up-modulated by the presence of endosymbiont in B. culicis [26].

In lower trypanosomatids two distinct cysteine-type peptidases were reported with biochemical/immunological similarities to corresponding enzymes produced by pathogenic flagellates designated as cruzipain-like (detected in B. culicis and $P$. serpens) and cpb-like (identified in H. samuelpessoai) 
[16, 26, 232]. Cruzipain-like molecules expressed by $P$. serpens were immunocytochemically evidenced along the whole extension of the membrane, coating the cell body and the flagellum, as well as in cytoplasmic compartments [16]. The $40 \mathrm{kDa}$ cruzipain-like molecule located at the $P$. serpens cell surface is attached to membrane domains via a GPI and fluorescence microscopy showed that cruzipain-like molecules were preferentially located on the posterior end of $P$. serpens cells, resembling $T$. cruzi cruzipain distribution [232].

Furthermore, calpain molecules containing some degrees of similarity with calpain produced by Drosophila melanogaster were also reported in two insect flagellates, $C$. deanei [25] and H. samuelpessoai [232]. Interestingly, the 80 $\mathrm{kDa}$ calpain-like molecules, produced by $C$. deanei cells, were purified from the culture filtrate, showing distinct properties from the well-characterized mammalian calpains, but some degree of similarity was displayed to invertebrate calpain-related enzymes [25]. In H. samuelpessoai, a $80 \mathrm{kDa}$ calpain-like molecule was identified and its expression was enhanced after DMSO-triggered differentiation, suggesting a participation during the process of promastigote into paramastigote transformation [232].

\section{Metallopeptidases: gp63-Like}

Gp63-like molecules expressed in lower trypanosomatids were detected on both cell-associated and secreted forms. Typically, the cellular gp63-like molecules were mainly attached to the cell surface by a GPI anchor; however, a small amount of this enzyme can be detected in cytoplasmic compartments, which may indicate the occurrence of hydrophilic isoforms, or the detection of enzymatic activity from precursor molecules that are further transported to the plasma membrane [13]. Curiously, two distinct populations with different affinities for the anti-gp63 antibody were identified in H. samuelpessoai, L. wallacei, C. deanei and C. guilher$m e i$ by means of flow cytometry analyses, indicating that gp63-related molecules are not equally expressed on the surface of trypanosomatid cells [19, 28, 231]. The lack of equal expression may be correlated to the parasites growth and/or cell cycle phases, since flagellate cultures were not synchronized. Furthermore, the occurrence of distinct subpopulations could alternatively denote a different expression of surface gp63-like molecules in the different developmental stages or even a diminished accessibility to external ligands in cell subsets, as previously reported for other trypanosomatid cell surface molecules [12, 27]. Conversely, the extracellular isoform can be released from parasite cells by two mechanisms that follow the classic secretory pathway with routing of gp63 from the endoplasmic reticulum to the Golgi network and then into the flagellar pocket. Vesicles containing both membrane-bound and free gp63 fuse with the flagellar pocket membrane and thereafter the free gp63 is released extracellularly [30], while the membrane-bound form is located throughout the external cell membrane and a proportion of this is released directly via autoproteolysis [19], in a similar mechanism to that observed in Leishmania [160, 161]. Both cellular and released gp63-like molecules had similar biochemical features, including optimum $\mathrm{pH}$ around 5.0-6.5 (the prevailing $\mathrm{pH}$ range of the insect gut and the $\mathrm{pH}$ of phagolysosome), susceptibility to metallo-type peptidase inhibitors mainly 1,10-phenanthroline, molecular mass around $50-70 \mathrm{kDa}$, immunological reactivity against antigp63 antibodies, best temperature at $37^{\circ} \mathrm{C}$ (mammalian temperature) instead of $26^{\circ} \mathrm{C}$ (invertebrate temperature) and broad hydrolytic capability (degrading gelatin, hemoglobin, casein, albumin, mucin, immunoglobulin and insect proteinaceous components), corroborating the hypothesis of conservation of an ancient and functionally relevant molecule shared by both heteroxenous and monoxenous trypanosomatids [15].

The gp63-like molecules contribute to adhesive processes in lower trypanosomatids. In this respect, binding assays with explanted guts or salivary glands of insects incubated with purified gp63 (in an active form or inactivated by heating or removal of essential ions from the active site) and the pre-treatment of trypanosomatids with anti-gp63 antibodies, metallopeptidase inhibitors or phospholipase $\mathrm{C}$ showed a reduced adhesion of these trypanosomatids to the insect gut wall or salivary glands, respectively (Fig. 2). At least to Aedes aegypti, a suitable experimental model to study the interaction of monoxenous trypanosomatids and insects, a receptor of $50 \mathrm{kDa}$ for the gp63 purified molecule was identified in the protein insect gut extract [28].

Another interesting remark regarding the monoxenous trypanosomatid is that some of them present a bacterium symbiont in their cytoplasm, conferring a suitable model for the symbiosis studies. It is well known that the symbiont interferes with several aspects of the host trypanosomatid physiology [233], including the production of proteolytic enzymes $[10,23,26]$. In this sense, previous studies showed that endosymbiont-bearing strains are more efficient in binding to insect cell lines and midguts, as compared to symbiotic free strains, which is probably related to differential expression of surface molecules [27, 234]. For example, the endosymbiont of $C$. deanei influences the expression of surface gp63 molecules. Additionally, the number of wild $C$. deanei bound to $A$. aegypti explanted guts was twice as many as those of aposymbiotic parasites. Flow cytometry assays revealed that the reactivity of the wild strain with anti- p63 antibodies was approximately double that of the aposymbiotic strain, suggesting that the higher expression of surface gp63 by the wild strain of $C$. deanei may positively influence this interaction, posing a prominent advantage for the endosymbiont-containing trypanosomatids [30]. In a similar way, the endosymbiont positively influenced the interaction of $C$. deanei with mammalian fibroblasts and the surface gp63-like molecules of this parasite were also implicated in this adhesive process [230].

\section{PERSPECTIVES}

Trypanosomatids elaborate a large array of peptidases, which are intracellular and/or extracellular, with different specificities and many of them have been purified and characterized and their genes cloned and sequenced. In this sense, much progress has been made in understanding peptidase function in protozoan parasites. We are gaining a fascinating picture of the often unique and the highly specialized roles of peptidases in these organisms, playing central functions in diverse processes such as nutrition, host cell invasion, catabolism of host proteins, parasite differentiation, cell cycle progression and both stimulation and evasion of host 


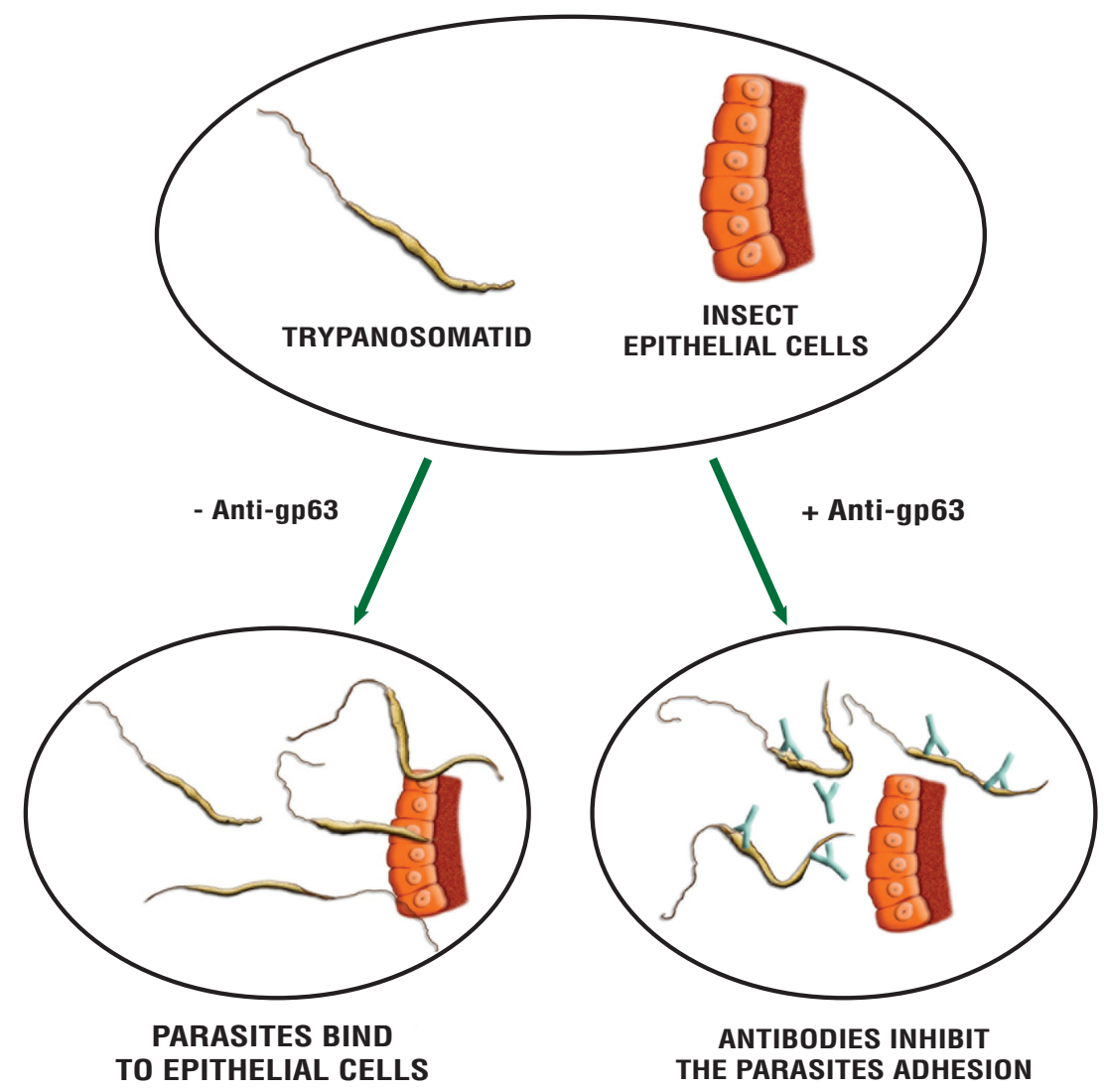

Fig. (2). The schematic representation shows a trypanosomatid cell expressing at the surface gp63-like molecules. The adhesion rate to the insect epithelium in vitro is evaluated in untreated (- anti-gp63) or parasites previously treated with anti-gp63 antibodies (+ anti-gp63). This treatment led to reduced levels of adhesion.

immune responses. In addition, because of their unusual structural features, developing a new generation of chemotherapeutic agents for parasitic diseases, such as Chagas' disease and leishmaniasis, is also a critical research priority. Furthermore, the lower trypanosomatids share similar molecules from classical trypanosomatid pathogens, including virulence factors like peptidases $[15,17]$. These observations indicate that the life cycle of lower trypanosomatids has been underestimated and that homologous to virulence attributes from pathogens should fulfill a more diverse role for these trypanosomatids than previously thought and confirm their importance as a model for biochemical and molecular studies among the trypanosomatids.

\section{ACKNOWLEDGMENTS}

We thank David Graham Straker for helpful comments on previous versions of the manuscript. Research done in the authors' laboratories, included in this review, was supported by grants and fellowships from FAPERJ, MCT-CNPq and CAPES. Address for reprint requests and other correspondence: Alane. B. Vermelho, Instituto de Microbiologia Prof. Paulo de Góes, UFRJ, Centro de Ciências da Saude, bloco I, Cidade Universitaria, 21949-900, Rio de Janeiro, RJ, Brazil [E-mail: abvermelho@ micro.ufrj.br].

\section{ABBREVIATIONS}
$\mathrm{CPs}=$ cysteine peptidases
gp63 = glycoprotein with $63 \mathrm{kDa}$

\section{REFERENCES}

[1] Araujo A, Jansen AM, Reinhard K, Ferreira LF. Paleoparasitology of Chagas disease: a review. Mem Inst Oswaldo Cruz 2009; 104: 9-16.

[2] Wallace FG. Trypanosomatid parasites of insects and arachnids. Exp Parasitol 1966; 18: 124-93.

[3] McGhee RB, Cosgrove WB. Biology and physiology of the lower Trypanosomatidae. Microbiol Rev 1980; 44: 140-73.

[4] Croft SL. Kinetoplastida: new therapeutic strategies. Parasite 2008; 15: 522-7.

[5] Branquinha $\mathrm{MH}$, Vermelho $\mathrm{AB}$, Goldenberg S, Bonaldo MC. Ubiquity of cysteine- and metalloproteinase in a wide range of trypanosomatids. J Eukaryot Microbiol 1996; 43: 131-5.

[6] Nogueira de Melo AC, Giovanni-de-Simmone S, Branquinha MH, Vermelho AB. Crithidia guilhermei: purification and partial characterization of a $62-\mathrm{kDa}$ extracellular metalloproteinase. Exp Parasitol 2001; 97: 1-8.

[7] Nogueira de Melo AC, d'Avila-Levy CM, Branquinha MH, Vermelho AB. Crithidia guilhermei: gelatin- and hemoglobindegrading extracelular metalloproteinases. Exp Parasitol 2002; 102: 150-6.

[8] Nogueira de Melo AC, d'Avila-Levy CM, Dias FA, et al. Peptidases and gp63-like proteins in Herpetomonas megaseliae: possible involvement in the adhesion to the invertebrate host. Int J Parasitol 2006; 36: 415-22.

[9] Santos ALS, Ferreira A, Franco VA, Alviano CS, Soares RMA. Characterization of proteinases in Herpetomonas anglusteri and Herpetomonas roitmani. Curr Microbiol 1999; 39: 61-4.

[10] Santos ALS, Abreu CM, Batista LM, Alviano CS, Soares RMA. Cell-associated and extracellular proteinases in Blastocrithidia culicis: influence of growth conditions. Curr Microbiol 2001; 43: 100-6. 
[11] Santos ALS, Abreu CM, Alviano CS, Soares RMA. Activation of the glycosylphosphatidylinositol-anchored membrane proteinases upon release from Herpetomonas samuelpessoai by phospholipase C. Curr Microbiol 2002a; 45: 293-98.

[12] Santos ALS, Rodrigues ML, Alviano CS, Soares RMA. Changes of sialomolecules during the dimethylsulfoxide-induced differentiation of Herpetomonas samuelpessoai. Parasitol Res 2002b; 88: 951-55.

[13] Santos ALS, Rodrigues ML, Alviano CS, Angluster J, Soares RMA. Herpetomonas samuelpessoai: dimethylsulfoxide-induced differentiation is influenced by proteinase expression. Curr Microbiol 2003; 46: 11-17.

[14] Santos ALS, Abreu CM, Alviano CS, Soares RMA. Use of proteolytic enzymes as an additional tool for trypanosomatid identification. Parasitology 2005; 130: 79-88.

[15] Santos ALS, Branquinha MH, d'Avila-Levy CM. The ubiquitous gp63-like metalloprotease from lower trypanosomatids: in the search for a function. An Acad Bras Ciênc 2006a; 78: 687-714.

[16] Santos ALS, d'Avila-Levy CM, Dias FA, et al. Phytomonas serpens: cysteine peptidase inhibitors interfere with growth, ultrastructure and host adhesion. Int J Parasitol 2006b; 36: 47-56.

[17] Santos ALS, d'Avila-Levy CM, Elias CGR, Vermelho AB, Branquinha MH. Phytomonas serpens: immunological similarities with the human trypanosomatid pathogens. Microbes Infect 2007; 9: 915-21.

[18] Santos ALS, Soares RMA, Alviano CS, Kneipp LF. Heterogeneous production of metallo-type peptidases in parasites belonging to the family Trypanosomatidae. Eur J Protistol 2008; 44: 103-13.

[19] Elias CGR, Pereira FM, Silva BA, Alviano CS, Soares RMA, Santos ALS. Leishmanolysin [gp63 metallopeptidase]-like activity extracellularly released by Herpetomonas samuelpessoai. Parasitology 2006; 132: 37-47.

[20] Elias CGR, Pereira FM, Dias FA, et al. Cysteine peptidases in the tomato trypanosomatid Phytomonas serpens: influence of growth conditions, similarities with cruzipain and secretion to the extracellular environment. Exp Parasitol 2008; 120: 343-52.

[21] Vermelho AB, Almeida FVS, Bronzato LS, Branquinha MH. Extracellular metalloproteinases in Phytomonas serpens. Can J Microbiol 2003; 49: 221-4.

[22] Almeida FVS, Giovanni-de-Simone S, Branquinha MH, Vermelho AB. Extracellular metalloproteinase activity in Phytomonas françai. Parasitol Res 2003; 89: 320-2.

[23] d'Avila-Levy CM, Nogueira de Melo AC, Vermelho AB, Branquinha MH. Differential expression of proteolytic enzymes in endosymbiont-harboring Crithidia species. FEMS Microbiol Lett 2001; 202: 73-7.

[24] d'Avila-Levy CM, Souza RF, Gomes RC, Vermelho AB, Branquinha $\mathrm{MH}$. A metalloproteinase extracellularly released by Crithidia deanei. Can J Microbiol 2003a; 49: 625-32.

[25] d'Avila-Levy CM, Souza RF, Gomes RC, Vermelho AB, Branquinha MH. A novel extracellular calcium-dependent cysteine proteinase from Crithidia deanei. Arch Biochem Biophys 2003b; 420: $1-8$.

[26] d'Avila-Levy CM, Araújo FM, Vermelho AB, Soares RMA, Santos ALS, Branquinha MH. Proteolytic expression in Blastocrithidia culicis: influence of the endosymbiont and similarities with virulence factors of pathogenic trypanosomatids. Parasitology 2005a; 130: 413-20.

[27] d'Avila-Levy CM, Silva BA, Hayashi EA, et al. Influence of the endosymbiont of Blastocrithidia culicis and Crithidia deanei on the glycoconjugate expression and on Aedes aegypti interaction. FEMS Microbiol Lett 2005b; 252: 279-86.

[28] d'Avila-Levy CM, Dias FA, Nogueira de Melo AC, et al. Insights on the role of gp63-like proteins in insect trypanosomatids. FEMS Microbiol Lett 2006a; 254: 149-56

[29] d'Avila-Levy CM, Santos LO, Marinho FA, et al. Gp63-like molecules in Phytomonas serpens: possible role on the insect interaction. Curr Microbiol 2006b; 52: 439-44.

[30] d'Avila-Levy CM, Santos LO, Marinho FA, et al. Crithidia deanei: influence of parasite gp63 homologue on the interaction of endosymbiont-harboring and aposymbiotic strains with Aedes aegypti midgut. Exp Parasitol 2008; 118: 345-53.
[31] Chicarro C, Alvar J. Lower trypanosomatids in HIV/AIDS patients. Ann Trop Med Parasitol 2003; 97: 75-80.

[32] Engman DM, Leon JS. Pathogenesis of Chagas heart disease: role of autoimmunity. Acta Trop 2002; 81: 123-32.

[33] Barrett MP, Burchmore RJ, Lazzari JO, Frasch AC, Cazzulo JJ, Krisna S. The trypanosomiases. Lancet 2003; 362: 1469-80.

[34] Tyler K, Miles MA. American Trypanosomiasis, London, United Kingdom: Kluwer Academic Publishers 2003; vol. 7: pp. 81-96.

[35] WHO Expert Committee. Control of Chagas disease. World Health Organization Technical Report Series. 2002; 905: i-vi, 1-109, Available at: http://www.who.int/neglecteddiseases/en/ [Acessed in September 2009].

[36] WHO - World Health Organization. Chagas disease. Seventeenth Programme Report UNDP/TDR, Geneva. 2005, http://www.who.int/neglecteddiseases/en/ [Acessed in September 2009].

[37] Yoshida N. Molecular mechanisms of Trypanosoma cruzi infection by oral route. Mem Inst Oswaldo Cruz 2009; 104: 101-7.

[38] Pereira KS, Schmidt FL, Guaraldo AM, Franco RM, Dias VL, Passos LA. Chagas' disease as a foodborne illness. J Food Prot 2009; 72: 441-6.

[39] Cazzulo JJ. Proteinases of Trypanosoma cruzi: potential targets for the chemotherapy of Chagas' desease. Curr Top Med Chem 2002; 2: $1261-71$

[40] Urbina JA. Chemotherapy of Chagas' disease. Curr Pharm Des 2002; 8: 287-95

[41] McKerrow JH, Doyle PS, Engel JC, et al. Two approaches to discovering and developing new drug for Chagas disease. Mem Inst Oswaldo Cruz 2009; 104: 263-9.

[42] Fèvre EM, Wissmann BV, Welburn SC, Lutumba P. The burden of human african trypanosomiasis. PLoS Negl Trop Dis 2008; 2: 1-7.

[43] Kennedy PG. The continuing problem of human African trypanosomiasis [sleeping sickness]. Ann Neurol 2008; 64: 116-26.

[44] WHO. Leishmaniasis, magnitude of the problem. 2008. Available from:

http://www.who.int/leishmaniasis/burden/magnitude/burden_magni tude/en/index.html/ [accessed: September 2009].

[45] Davies CR, Kaye P, Croft SL, Sundar S. Leishmaniasis: new approaches to disease control. Br Med J 2003; 326: 377-82.

[46] Sharma U, Singh S. Immunobiology of leishmaniasis. Indian J Exp Biol 2009; 47: 412-23.

[47] Chaudhary RG, Bilimoria FE, Katare SK. Diffuse cutaneous leishmaniasis: co-infection with human immunodeficiency virus [HIV]. Indian J Dermatol Venereol Leprol 2008; 74: 641-3.

[48] Vickerman K. The evolutionary expansion of the trypanosomatid flagellates. Int J Parasitol 1994; 24: 1317-31.

[49] Camargo EP. Phytomonas and other trypanosomatid parasites of plants and fruit. Adv Parasitol 1999; 42: 29-112

[50] Cunha M, Gomes VM, Xavier-Filho J, Attias M, de Souza W, Miguens FC. The laticifer system of Chamaesyce thymifolia: a closed host environment for plant trypanosomatids. Biocell 2000; 24: 123-32.

[51] Podlipaev S. Insect trypanosomatids: the need to know more. Mem Inst Oswaldo Cruz 2002; 95: 517-22.

[52] Vermelho AB, Giovanni-de-Simone S, d'Avila-Levy CM, et al. Trypanosomatidae peptidases: a target for drugs development. Curr Enzyme Inhib 2007; 3: 19-48.

[53] Vermelho AB, Nogueira de Melo AC, Soares RA, et al. Trypanosoma cruzi Peptidases: An Overview. Open Parasitol J 2009; 3: 9 20.

[54] Rawlings ND, Morton FR, Kok CY, Kong J, Barrett AJ. MEROPS the peptidase database. Nucleic Acids Res 2008; 36: D320-D325.

[55] Mittl PR, Grütter MG. Opportunities for structure-based design of protease-directed drugs. Curr Opin Struct Biol 2006; 16: 769-75.

[56] Cazzulo JJ, Labriola C, Parussini F, Duschak VG, Martinez J, Franke de Cazzulo BM. Cysteine proteinase in Trypanosoma cruzi and other trypanosomatid protozoa. Acta Chim Slov 1995; 42: 4098 .

[57] Mottram JC, Coombs GH, Alexander J. Cysteine peptidases as virulence factors of Leishmania. Curr Opin Microbiol 2004; 7: 37581. 
[58] Murta AC, Persechini PM, Padron TS, de Souza W, Guimaraes JA, Scharfstein J. Structural and functional identification of gp57/51 antigen of Trypanosoma cruzi as a cysteine proteinase. Mol Biochem Parasitol 1990; 43: 27-38.

[59] Paiva CN, Souto-Padron T, Costa DA, Gattass CR. High expression of a functional cruzipain by a non-infective and nonpathogenic Trypanosoma cruzi clone. Parasitology 1998; 117: 48390.

[60] Villalta F, Scharfstein J, Ashton AW, et al. Perspectives on the Trypanosoma cruzi-host cell receptor interactions. Parasitol Res 2009; 104: 1251-60.

[61] Scharfstein J, Rodrigues MM, Alves CA, Souza W, Previato JO, Mendonça-Previato L. Trypanosoma cruzi: description of a highly purified surface antigen defined by human antibodies. J Immunol 1983; 131: 972-76.

[62] Scharfstein J, Luguetti A, Murta ACM, et al. Chagas'disease: serodiagnosis with purified Gp25 antigen. Am J Trop Med Hyg 1985; 34: 1153-61.

[63] Barbosa HS, Meirelles MN. Evidence of participation of cytoskeleton of heart muscle cells during the invasion of Trypanosoma cruzi. Cell Struct Funct 1995; 20: 275-84.

[64] Acosta DM, Arnaiz MR, Esteva MI, et al. Sulfates are main targets of immune responses to cruzipain and are involved in heart damage in BALB/c immunized mice. Int Immunol 2008; 20: 461-70.

[65] Souto-Padrón T, Campetella OE, Cazzulo JJ, de Souza W. Cysteine proteinase in Trypanosoma cruzi: immunocytochemical localization and involvement in parasite-host cell interaction. J Cell Sci 1990; 96: 485-90.

[66] Cazzulo JJ, Stoka V, Turk V. Cruzipain, the major cysteine proteinase from the protozoan parasite Trypanosoma cruzi. J Biol Chem 1997; 378:1-10.

[67] Meirelles MNL, Juliano L, Carmona E, et al. Inhibitors of the major cysteinyl proteinase (GP57/51) impair host cell invasion and arrest the intracellular development of Trypanosoma cruzi in vitro.Mol Biochem Parasitol 1992; 52: 175-84.

[68] Engel JC, Doyle PS, Palmer J, Hsieh I, Bainton DF, McKerrow JH. Cysteine protease inhibitors alter Golgi complex ultrastructure and function in Trypanosoma cruzi. J Cell Sci 1998; 111: 597-606.

[69] Caffrey CR, Scory S, Steverding D. Cysteine proteinases of trypanosome parasites: novel targets for chemotherapy. Curr Drug Targets 2000; 1: 155-62.

[70] Scharfstein J, Gomes JAS, Correa-Oliveira R. Back to the future in Chagas disease: from animal models to patient cohort studies, progress in immunopathogenesis research. Mem Inst Oswaldo Cruz 2009; 104: 187-98.

[71] Del Nery E, Juliano MA, Lima APCA, Scharfstein J, Juliano L. Kininogenase activity by major cysteinyl proteinase (Cruzipain) from Trypanosoma cruzi. J Biol Chem 1997; 272: 25713-8.

[72] Scharfstein J, Schmitz V, Morandi V, et al. Host cell invasion by Trypanosoma cruzi is potentiated by activation of bradykinin B2 receptors. J Exp Med 2000; 192: 1289-99.

[73] Lima AP, Almeida PC, Tersariol IL, et al. Heparan sulfate modulates kinin release by Trypanosoma cruzi through the activity of cruzipain. J Biol Chem 2002; 277: 5875-81.

[74] Aliberti J, Viola JP, Vieira-de-Abreu A, Bozza PT, Sher A, Scharfstein J. Cutting edge: bradykinin induces IL-12 production by dendritic cells: a danger signal that drives Th1 polarization. J Immunol 2003; 170: 5349-53.

[75] Monteiro AC, Schmitz V, Svensjo E, et al. Cooperative activation of TLR2 and bradykinin B2 receptor is required for induction of type 1 immunity in a mouse model of subcutaneous infection by Trypanosoma cruzi. J Immunol 2006; 177: 6325-35.

[76] Todorov AG, Andrade D, Pesquero JB, et al. Trypanosoma cruzi induces edematogenic responses in mice and invades cardiomyocytes and endothelial cells in vitro by activating distinct kinin receptor (B1/B2) subtypes. FASEB J 2003; 17: 73-5.

[77] Santos CC, Sant'anna C, Terres A, Cunha-e-Silva NL, Scharfstein J, de A Lima AP. Chagasin, the endogenous cysteine-protease inhibitor of Trypanosoma cruzi, modulates parasite differentiation and invasion of mammalian cells. J Cell Sci 2005; 118: 901-15.
[78] Garcia MP, Nóbrega OT, Teixeira ARL, Sousa MV, Santana JM. Characterisation of a Trypanosoma cruzi acidic $30 \mathrm{kDa}$ cysteine protease. Mol Biochem Parasitol 1998; 91: 263-72.

[79] Yong V, Schmitz V, Vannier-Santo MA, Lima AP, Lamanach G, Juliano L. Altered expression of cruzipain and a cathepsin B-like target in a Trypanosoma cruzi cell line displaying resistance to synthetic inhibitors of cysteine-proteinases. Mol Biochem Parasitol 2000; 109: 47-59.

[80] Duschak VG, Barboza M, García GA, Lammel EM, Couto AS, Isola ELD. Novel cysteine proteinase in Trypanosoma cruzi metacyclogenesis. Parasitology 2006; 132: 1-11.

[81] Goll DE, Thompson VF, Li H, Wei W, Cong J. The calpain system. Physiol Rev 2003; 83: 731-801.

[82] Ono Y, Sorimachi H, Suzuki K. Structure and physiology of calpain, an enigmatic protease. Biochem Biophys Res Commun 1998 245: 289-94.

[83] Giese V, Dallagiovanna B, Marchini FK, Pavoni DP, Krieger MA, Goldenberg S. Trypanosoma cruzi: a stage-specific calpain-like protein is induced after various kinds of stress. Mem Inst Oswaldo Cruz 2008; 103: 598-601.

[84] Sorimachi H, Ishiura S, Suzuki K. Structure and physiologicalfunctions of calpains. Biochem J 1997; 328: 721-32.

[85] Branca D. Calpain-related diseases. Biochem Biophys Res Commun 2004; 322: 1098-104.

[86] Ivens AC, Peacock CS, Worthey EA, et al. The genome of the kinetoplastid parasite, Leishmania major. Science 2005; 309: 43642.

[87] Sangenito LS, Ennes-Vidal V, Marinho FA, et al. Arrested growth of Trypanosoma cruzi by the calpain inhibitor MDL28170 and detection of calpain homologues in epimastigote forms. Parasitology 2009; 136: 433-41.

[88] Mottram JC, Helms MJ, Coombs GH, Sajid M. Clan CD cysteine peptidases of parasitic protozoa. Trends Parasitol 2003; 19: 182-7.

[89] Szallies A, Kubata BK, Duszenko M. A metacaspase of Trypanosoma brucei causes loss of respiration competence and clonal death in the yeast Saccharomyces cerevisiae. FEBS Lett 2002; 517: 14450 .

[90] Helms MJ, Ambit A, Appleton P, Tetley L, Coombs GH, Mottram JC. Bloodstream form Trypanosoma brucei depend upon multiple metacaspases associated with RAB11-positive endosomes. J Cell Sci 2006; 119: 1105-17.

[91] Kosec G, Alvarez VE, Agüero F, et al. Metacaspases of Trypanosoma cruzi: possible candidates for programmed cell death mediators. Mol Biochem Parasitol 2006;145:18-28.

[92] Gonzalez J, Desponds C, Schaff C, Mottram JC, Fasel N. Leishmania major metacaspase can replace yeast metacaspase in programmed cell death and has arginine-specific cysteine peptidase activity. Int J Parasitol 2007; 37: 161-72.

[93] Ambit A, Fasel N, Coombs GH, Mottram JC. An essential role for the Leishmania major metacaspase in cell cycle progression. Cell Death Differ 2008; 15: 113-22.

[94] El-Sayed NM, Myler PJ, Bartholomeu DC, et al. The genome sequence of Trypanosoma cruzi, etiologic agent of Chagas disease. Science 2005; 309: 409-15.

[95] Jimenez V, Paredes R, Sosa MA, Galanti N. Natural programmed cell death in $T$. cruzi epimastigotes maintained in axenic cultures. $\mathrm{J}$ Cell Biochem 2008; 105: 688-98.

[96] Bonaldo MC, d'Escoffier LN, Salles JM, Goldenberg S. Characterization and expression of proteases during Trypanosoma cruzi metacyclogenesis. Exp Parasitol 1991; 73: 44-51.

[97] Lowndes CM, Bonaldo MC, Thomaz N, Goldenberg S. Heterogeneity of metalloprotease expression in Trypanosoma cruzi. Parasitology 1996; 112: 393-99.

[98] Cuevas IC, Cazzulo JJ, Sánchez DO. gp63 homologues in Trypanosoma cruzi: surface antigens with metalloprotease activity and a possible role in host cell infection. Infect Immun 2003; 71: 5739-49.

[99] Nogueira de Melo AC, Meirelles MNL, Porrozzi R, Costa JD, Branquinha MH, Vermelho AB. Reduced activity of matrix metalloproteinase-9 in Trypanosoma cruzi infected mouse embryo hepatocyte cell. Hepatol Res 2004; 28: 49-56. 
[100] Niemirowicz G, Parussini F, Agüero F, Cazzulo JJ. Two metallocarboxypeptidases from the protozoan Trypanosoma cruzi belong to the M32 family, found so far only in prokaryotes. Biochem J 2007; 401: 399-410.

[101] Niemirowicz G, Fernández D, Solà M, Cazzulo JJ, Avilés FX, Gomis-Rüth FX. The molecular analysis of Trypanosoma cruzi metallocarboxypeptidase 1 provides insight into fold and substrate specificity. Mol Microbiol 2008; 70: 853-66.

[102] Kulkarni MM, Olson CL, Engman DM, McGwire BS. Trypanosoma cruzi GP63 proteins undergo stage-specific differential posttranslational modification and are important for host cell infection. Infect Immun 2009; 77: 2193-200.

[103] Cockle JA, Gopichandran N, Walker JJ, Levene MI, Orsi NM. Matrix metalloproteinases and their tissue inhibitors in preterm perinatal complications. Reprod Sci 2007; 14: 629-45.

[104] Wojtowicz-Praga SM, Dickson RB, Hawkins MJ. Matrix metalloproteinase inhibitors. Invest New Drugs 1997; 15: 61-75.

[105] Mastroianni CM, Liuzzi GM. Matrix metalloproteinase dysregulation in HIV infection: implications for therapeutic strategies. Trends Mol Med 2007; 13: 449-59.

[106] Marchant D, McManus B. Matrix metalloproteinases in the pathogenesis of viral heart disease. Trends Cardiovasc Med 2009; 19: 21-26.

[107] Cauwe B, Van den Steen PE, Opdenakker G. The biochemical, biological, and pathological kaleidoscope of cell surface substrates processed by matrix metalloproteinases. Crit Rev Biochem Mol Biol 2007; 42: 113-85.

[108] Marin-Neto JA, Cunha-Neto E, Maciel BC, Simoes MV. Pathogenesis of chronic Chagas heart disease. Circulation 2007; 115: 110923.

[109] Punukollu G, Gowda RM, Khan IA, Navarro VS, Vasavada BC. Clinical aspects of the Chagas' heart disease. Int J Cardiol 2007; 115: 279-83.

[110] Gutierrez FR, Mariano FS, Lalu MM, et al. Increased activities of cardiac matrix metalloproteinases matrix metalloproteinase (MMP)-2 and MMP-9 are associated with mortality during the acute phase of experimental Trypanosoma cruzi infection. J Infect Dis 2008; 197: 1468-76.

[111] Burleigh B, Andrews N. A 120-kDa alkaline peptidase from Trypanosoma cruzi is involved in the generation of a novel $\mathrm{Ca}^{2+}-$ signaling factor for mammalian cells. J Biol Chem 1995; 270: 5172-80.

[112] Burleigh B, Caler EV, Webster P, Andrews N. A cytosolic serine endopeptidase from Trypanosoma cruzi is required for the generation of $\mathrm{Ca}^{2+}$-signaling in mammalian cells. J Cell Biol 1997; 136: 609-20.

[113] Caler EV, Vaena de Avalos S, Haynes PA, Andrews NW, Burleigh BA. Oligopeptidase B-dependent signaling mediates host cell invasion by Trypanosoma cruzi. EMBO J 1998; 17: 4975-86.

[114] Fernandes LC, Bastos MDI, Lauria-Pires L, et al. Specific human antibodies do not inhibit Trypanosoma cruzi oligopeptidase B and cathepsin B, and immunoglobulin $\mathrm{G}$ enhances the activity of trypomastigote-secreted oligopeptidase B. Microbes Infect 2005; 7: 375-84.

[115] Santana JM, Grellier P, Schrevel J, Teixeira AR. A Trypanosoma cruzi-secreted $80 \mathrm{kDa}$ proteinase with specificity for human collagen types I and IV. Biochem J 1997; 325:129-37.

[116] Grellier P, Vendeville S, Joyeau R, et al. Trypanosoma cruzi prolyl oligopeptidase Tc80 isinvolved in nonphagocytic mammalian cell invasion by trypomastigotes. J Biol Chem 2001; 276: 47078-80.

[117] Bastos IM, Grellier P, Martins NF, et al. Molecular, functional and structural properties of the prolyl oligopeptidase of Trypanosoma cruzi (POP Tc80), which is required for parasite entry into mammalian cells. Biochem J 2005; 388: 29-38.

[118] Ponder EL, Bogyo M. Ubiquitin-like modifiers and their deconjugating enzymes in medically important parasitic protozoa. Eukaryot Cell 2007; 6: 1943-52.

[119] Kirchhoff LV, Kim KS, Engman DM, Donelson JE. Ubiquitin genes in trypanosomatidae. J Biol Chem 1988; 263:12698-704.

[120] Swindle J, Ajioka J, Eisen H, et al. The genomic organization and transcription of the ubiquitin genes of Trypanosoma cruzi. EMBO J 1988; 7: 1121-7.
[121] de Diego JL, Katz JM, Marshall P, et al. The ubiquitin-proteasome pathway plays an essential role in proteolysis during Trypanosoma cruzi remodeling. Biochemistry 2001; 40: 1053-62.

[122] Nkemgu-Njinkeng J, Rosenkranz V, Wink M, Steverding D. Antitrypanosomal activities of proteasome inhibitors. Antimicrob Agents Chemother 2002; 46: 2038-40.

[123] González IJ, Ramalho-Pinto FJ, Frevert U, et al. Proteasome activity is required for the stage-specific transformation of a protozoan parasite. J Exp Med 1996; 184: 1909-18.

[124] Cardoso J, Soares MJ, Menna-Barreto RFS, et al. Inhibition of proteasome activity blocks Trypanosoma cruzi growth and metacyclogenesis. Parasitol Res 2008; 103: 941-51.

[125] Rock KL, Gramm C, Rothstein L, et al. Inhibitors of the proteasome block the degradation of most cell proteins and the generation of peptides presented on MHC class I molecules. Cell 1994; 78: 761-71.

[126] Kloetzel, PM. Antigen processing by the proteasome. Nat Rev Mol Cell Biol 2001; 2: 179-87.

[127] Faria LO, Lima BD, de Sá CM. Trypanosoma cruzi: effect of the infection on the 20S proteasome in non-immune cells. Exp Parasitol 2008; 120: 261-8.

[128] Gutiérrez B, Osorio L, Motta MC, et al. Molecular characterization and intracellular distribution of the alpha 5 subunit of Trypanosoma cruzi 20S proteasome. Parasitol Int 2009; 58: 367-74.

[129] Pinho RT, Beltramini LM, Alves CR, De-Simone SG. Trypanosoma cruzi: Isolation and characterization of aspartyl proteases. Exp Parasitol 2009; 122: 128-33.

[130] Mottram JC, Souza AE, Hutchison JE, Carter R, Frame MJ, Coombs GH. Evidence from disruption of the $1 \mathrm{mcpb}$ gene array of Leishmania mexicana that cysteine proteinases are virulence factors. Proc Natl Acad Sci USA 1996; 93: 6008-13.

[131] Mottram JC, Frame MJ, Brooks DR, et al. The multiple cpb cysteine proteinase genes of Leishmania mexicana encode isoenzymes that differ in their stage regulation and substrate preferences. J Biol Chem 1997; 272: 14285-93

[132] Brooks DR, Denise H, Westrop GD, Coombs GH, Mottram JC. The stage-regulated expression of Leishmania mexicana CPB cysteine proteases is mediated by an intercistronic sequence element. J Biol Chem 2001; 276: 47061-9.

[133] Alexander J, Coombs GH, Mottram JC. Leishmania mexicana cysteine proteinase-deficient mutants have attenuated virulence for mice and potentiate a Th1 response. J Immunol 1998; 161: 6794801.

[134] Frame MJ, Mottram JC, Coombs GH. Analysis of the roles of cysteine proteinases of Leishmania mexicana in the host-parasite interaction. Parasitology 2000; 121: 367-77.

[135] Denise H, McNeil K, Brooks DR, Alexander J, Coombs GH, Mottram JC. Expression of multiple CPB genes encoding cysteine proteases is required for Leishmania mexicana virulence in vivo. Infect Immun 2003; 71: 3190-5.

[136] Williams RA, Tetley L, Mottram JC, Coombs GH. Cysteine peptidases CPA and CPB are vital for autophagy and differentiation in Leishmania mexicana. Mol Microbiol 2006; 61: 655-74.

[137] Santos LO, Marinho FA, Altoé EF, et al. HIV aspartyl peptidase inhibitors interfere with cellular proliferation, ultrastructure and macrophage infection of Leishmania amazonensis. PLoS One 2009; 4: e4918.

[138] Omara-Opyene AL, Gedamu L. Molecular cloning, characterization and overexpression of two distinct cysteine protease cDNAs from Leishmania donovani chagasi. Mol Biochem Parasitol 1997; 90: 247-67.

[139] Mundodi V, Somanna A, Farreli PJ, Gedamu L. Genomic organization and functional expression of differentially regulated cysteine protease genes of Leishmania donovani complex. Gene 2002; 282: 257-65.

[140] Mundodi V, Kucknoor AS, Gedamu L. Role of Leishmania [Leishmania] chagasi amastigote cysteine protease in intracellular parasite survival: studies by gene disruption and antisense mRNA inhibition. BMC Mol Biol 2005; 6:3.

[141] Svensjo E, Batista PR, Brodskyn CI, et al. Interplay between parasite cysteine proteases and the host kinin system modulates micro- 
vascular leakage and macrophage infection by promastigotes of the Leishmania donovani complex. Microbes Infect 2006; 8: 206-20.

[142] Alves CR, Marzochi MC, Giovanni-De-Simone. Heterogeneity of cysteine proteinases in Leishmania braziliensis and Leishmania major. Braz J Med Biol Res 1993; 26: 167-71.

[143] Rebello KM, Côrtes LM, Pereira BA, et al. Cysteine proteinases from promastigotes of Leishmania [Viannia] braziliensis. Parasitol Res 2009; [Epub ahead of print].

[144] Lima AK, Elias CG, Souza JE, Santos ALS, Dutra PM. Dissimilar peptidase production by avirulent and virulent promastigotes of Leishmania braziliensis: inference on the parasite proliferation and interaction with macrophages. Parasitology 2009; 136: 1179-91.

[145] Lanfranco MF, Loayza-Muro R, Clark D, et al. Expression and substrate specificity of a recombinant cysteine proteinase $\mathrm{B}$ of Leishmania braziliensis. Mol Biochem Parasitol 2008; 161: 91100.

[146] Azizi H, Hassani K, Taslimi Y, Najafabadi HS, Papadopoulou B, Rafati S. Searching for virulence factors in the non-pathogenic parasite to humans Leishmania tarentolae. Parasitology 2009; 136: 723-35.

[147] Morio F, Reynes J, Dollet M, Pratlong F, Dedet JP, Ravel C. Isolation of a protozoan parasite genetically related to the insect trypanosomatid Herpetomonas samuelpessoai from a human immunodeficiency virus-positive patient. J Clin Microbiol 2008; 46: 3845-7.

[148] Ersfeld K, Barraclough H, Gull K. Evolutionary relationships and protein domain architecture in an expanded calpain superfamily in kinetoplastid parasites. J Mol Evol 2005; 61: 742-57.

[149] Saxena A, Worthey EA, Yan S, Leland A, Stuart KD, Myler PJ. Evaluation of differential gene expression in Leishmania major Friedlin procyclics and metacyclics using DNA microarray analysis. Mol Biochem Parasitol 2003; 129: 103-14.

[150] d'Avila-Levy CM, Marinho FA, Santos LO, Martins JL, Santos ALS, Branquinha MH. Antileishmanial activity of MDL 28170, a potent calpain inhibitor. Int J Antimicrob Agents 2006c; 28: 13842.

[151] Vergnes B, Gourbal B, Girard I, Sundar S, Drummelsmith J, Ouellette M. A proteomics screen implicates HSP83 and a small kinetoplastid calpain-related protein in drug resistance in Leishmania donovani clinical field isolates by modulating drug-induced programmed cell death. Mol Cell Proteomics 2007; 6: 88-101.

[152] Salotra P, Duncan RC, Singh R, Subba Raju BV, Sreenivas G, Nakhasi HL. Upregulation of surface proteins in Leishmania donovani isolated from patients of post kala-azar dermal leishmaniasis. Microbes Infect 2006; 8: 637-44.

[153] Dey R, Bhattacharya J, Datta SC. Calcium-dependent proteolytic activity of a cysteine protease caldonopain is detected during Leishmania infection. Mol Cell Biochem 2006; 281: 27-33.

[154] Etges R. Identification of a surface metalloproteinase on 13 species of Leishmania isolated from humans, Crithidia fasciculata, and Herpetomonas samuelpessoai. Acta Trop 1992; 50: 20-17.

[155] Fong D, Chang KP. Surface antigenic change during differentiation of a parasite protozoan, Leishmania mexicana: identification by monoclonal antibodies. Proc Natl Acad Sci USA 1982; 79: 736670 .

[156] Yao C, Donelson JE, Wilson ME. The major surface protease [MSP or GP63] of Leishmania sp. Biosynthesis, regulation of expression, and function. Mol Biochem Parasitol 2003; 132: 1-16.

[157] Bouvier J, Etges RJ, Bordier C. Identification and purification of membrane and soluble forms of the major surface protein of Leishmania promastigotes. J Biol Chem 1985; 260: 15504-9.

[158] Weise F, Stierhof YD, Kuhn C, Wiese M, Overath P. Distribution of GPI-anchored proteins in the protozoan parasite Leishmania, based on an improved ultrastructural description using highpressure frozen cells. J Cell Sci 2000; 113: 4587-603.

[159] Chang CS, Inserra TJ, Kink JA, Fong D, Chang KP. Expression and size heterogeneity of a $63 \mathrm{kDa}$ membrane glycoprotein during growth and transformation of Leishmania mexicana amazonensis. Mol Biochem Parasitol 1986; 18: 197-210.

[160] McGwire BS, O'Connell WA, Chang KP, Engman DM. Extracellular release of the glycosylphosphatidylinositol [GPI]-linked
Leishmania surface metalloprotease, gp63, is independent of GPI phospholipolysis. J Biol Chem 2002; 277: 8802-9.

[161] Yao C, Leidal KG, Brittingham A, Tarr DE, Donelson JE, Wilson ME. Biosynthesis of the major surface protease GP63 of Leishmania chagasi. Mol Biochem Parasitol 2002; 121:119-28.

[162] Button LL, McMaster WR. Molecular cloning of the major surface antigen of Leishmania. J Exp Med 1988; 167: 724-9.

[163] Button LL, Russell DG, Klein HL, Medina-Acosta E, Karess R McMaster WR. Genes encoding the major surface glycoprotein in Leishmania are tandemly linked at a single chromosomal locus and are constitutively transcribed. Mol Biochem Parasitol 1989; 32: 271-84.

[164] Schlagenhauf E, Etges E, Metcalf P. The crystal structure of the Leishmania major surface proteinase leishmanolysin [gp63]. Structure 1998; 6: 1035-46.

[165] Bouvier J, Bordier C, Vogel H, Reichelt R, Etges RJ. Characterization of the promastigote surface protease of Leishmania as a membrane-bound zinc endopeptidases. Mol Biochem Parasitol 1989; 37 : 235-45.

[166] Medina-Acosta E, Karess RE, Russell DG. Structurally distinct genes for the surface protease of Leishmania mexicana are developmentally regulated. Mol Biochem Parasitol 1993; 57: 31-46.

[167] McGwire BS, Chang KP, Engeman DM. Migration through the extracellular matrix by the parasitic protozoan Leishmania is enhanced by surface metalloprotease gp63. Infect Immun 2003; 71: 1008-10.

[168] Chaudhuri G, Chang KP. Acid protease activity of a major surface membrane glycoprotein [gp63] from Leishmania mexicana promastigotes. Mol Biochem Parasitol 1988; 27: 43-52.

[169] Brittingham A, Morrison CJ, McMaster WR, McGwire BS, Chang KP, Mosser DM. Role of the Leishmania surface protease gp63 in complement fixation, cell adhesion, and resistance to complementmediated lysis. J Immunol 1995; 155: 3102-11.

[170] Mosser D, Edelson PJ. The third component of complement [C3] is responsible for the intracellular survival of Leishmania major. Nature 1987; 327: 329-31.

[171] Russell DG, Talamas-Rohana P, Zelechowski J. Antibodies raised against synthetic peptides from the Arg-Gly-Asp-containing region of the Leishmania surface protein gp63 cross-react with human C3 and interfere with gp63-mediated binding to macrophages. Infect Immun 1989; 57: 630-2.

[172] Soteriadou KP, Remounds MS, Katsikas MC, et al. The Ser-ArgTyr-Asp region of the major surface glycoprotein of Leishmania mimics the Arg-Gly-Asp-Ser cell attachment region of fibronectin. J Biol Chem 1992; 267: 13980-5.

[173] Corradin S, Ransijn A, Corradin G, et al. MARCKS-related protein [MRP] is a substrate for the Leishmania major surface protease leishmanolysin [gp63]. J Biol Chem 1999; 274: 25411-8.

[174] Hey AS, Theander TG, Hviid L, Hazrati SM, Kemp M, Kharazmi A. The major surface glycoprotein [gp63] from Leishmania major and Leishmania donovani cleaves CD4 molecules on human T cells. J Immunol 1994; 152: 4542-8.

[175] Garcia MR, Graham S, Harris RA, Beverley SM, Kayne PM. Epitope cleavage by Leishmania endopeptidases[s] limits the efficiency of the exogenous pathway of major histocompatibility complex class I-associated antigen presentation. Eur J Immunol 1997; 27: $1005-13$.

[176] Grimm F, Jenni L, Bouvier J, Etges RJ, Bordier C. The promastigote surface protease of Leishmania donovani infantum in the midgut of Phlebhotomus perniciosus. Acta Trop 1987; 44: 375-7.

[177] Davies CR, Cooper AM, Peacock C, Lane RP, Blackwell JM. Expression of LPG and GP63 by different developmental stages of Leishmania major in the sandfly Phlebotomus papatasi. Parasitology 1990; 101: 337-43.

[178] Joshi PB, Kelly BL, Kamhawi S, Sacks DL, McMaster WR. Targeted gene deletion in Leishmania major identifies leishmanolysin [GP63] as a virulence factor. Mol Biochem Parasitol 2002; 120: 33-40.

[179] Hajmová M, Chang KP, Kolli B, Volf P. Down-regulation of gp63 in Leishmania amazonensis reduces its early development in Lutzomyia longipalpis. Microb Infect 2004, 6: 646-9. 
[180] Costa JD, Nogueira de Melo AC, Vermelho AB, Meirelles MN, Porrozzi R. In vitro evidence for metallopeptidase participation in hepatocyte damage induced by Leishmania chagasi-infected macrophages. Acta Trop 2008; 106: 175-83.

[181] Almeida-Campos FR, Horta MF. Proteolytic activation of leishporin: evidence that Leishmania amazonensis and Leishmania guyanensis have distinct inactive forms. Mol Biochem Parasitol 2000; 111: 363-75.

[182] Alphey MS, Williams RA, Mottram JC, Coombs GH, Hunter WN. The crystal structure of Leishmania major 3-mercaptopyruvate sulfurtransferase: a three-domain architecture with a serine proteaselike triad at the active site. J Biol Chem 2003; 278: 48219-27.

[183] Silva-Lopez RE, Morgado-Díaz JA, Alves CR, Côrte-Real S, Giovanni-De-Simone S. Subcellular localization of an extracellular serine protease in Leishmania [Leishmania] amazonensis. Parasitol Res 2004a; 93: 328-31.

[184] Silva-Lopez RE, Giovanni-De-Simone S. Leishmania [Leishmania] amazonensis: purification and characterization of a promastigote serine protease. Exp Parasitol 2004b; 107: 173-82.

[185] Morgado-Díaz JA, Silva-Lopez RE, Alves CR, Soares MJ, CorteReal S, De Simone SG. Subcellular localization of an intracellular serine protease of $68 \mathrm{kDa}$ in Leishmania [Leishmania] amazonensis promastigotes. Mem Inst Oswaldo Cruz 2005; 100: 377-83.

[186] Silva Lopez RE, De Simone SG. A serine protease from a detergent-soluble extract of Leishmania [Leishmania] amazonensis. Z Naturforsch C 2004c; 59: 590-8.

[187] Silva-Lopez RE, Coelho MG, De Simone SG. Characterization of an extracellular serine protease of Leishmania [Leishmania] amazonensis. Parasitology 2005; 131: 85-96.

[188] Guedes HL, Rezende JM, Fonseca MA, Salles CM, RossiBergmann B, De-Simone SG. Identification of serine proteases from Leishmania braziliensis. Z Naturforsch C 2007; 62: 373-81.

[189] Choudhury R, Bhaumik SK, De T, Chakraborti T. Identification, purification, and characterization of a secretory serine protease in an Indian strain of Leishmania donovani. Mol Cell Biochem 2009; 320: 1-14.

[190] Silva-Lopez RE, Morgado-Díaz JA, Chávez MA, Giovanni-DeSimone S. effects of serine protease inhibitors on viability and morphology of Leishmania [Leishmania] amazonensis promastigotes. Parasitol Res 2007; 101: 1627-35.

[191] Alves CR, Corte-Real S, Bourguignon SC, Chaves CS, Saraiva EM. Leishmania amazonensis: early proteinase activities during promastigote-amastigote differentiation in vitro. Exp Parasitol 2005; 109: 38-48.

[192] Valdivieso E, Dagger F, Rascón A. Leishmania mexicana: identification and characterization of an aspartyl proteinase activity. Exp Parasitol 2007; 116: 77-82.

[193] Alvar J, Aparicio P, Aseffa A, et al. The relationship between leishmaniasis and AIDS: the second 10 years. Clin Microbiol Rev 2008; 21: 334-59.

[194] Pozio E, Morales MA. The impact of HIV-protease inhibitors on opportunistic parasites. Trends Parasitol 2005; 21: 58-63.

[195] Savoia D, Allice T, Tovo PA. Antileishmanial activity of HIV protease inhibitors. Int J Antimicrob Agents 2005; 26: 92-4.

[196] Trudel N, Garg R, Messier N, Sundar S, Ouellette M, Tremblay MJ. Intracellular survival of Leishmania species that cause visceral leishmaniasis is significantly reduced by HIV-1 protease inhibitors. J Infect Dis 2008; 198: 1292-9.

[197] Schubert U, Antón LC, Gibbs J, Norbury CC, Yewdell JW, Bennink JR. Rapid degradation of a large fraction of newly synthesized proteins by proteasomes. Nature 2000; 404: 770-4.

[198] Groll M, Huber R. Inhibitor-binding mode of homobelactosin C to proteasomes: new insights into class I MHC ligand generation. Biochim Biophys Acta 2004; 1695: 33-44.

[199] Robertson CD. The Leishmania mexicana proteasome. Mol Biochem Parasitol 1999; 103: 49-60.

[200] Fenteany G, Standaert RF, Lane WS, Choi S, Corey EJ, Schreiber SL. Inhibition of proteasome activities and subunit-specific aminoterminal threonine modification by lactacystin. Science 1995; 268: 726-31.

[201] Lonsdale-Eccles JD, Mpimbaza GWN. Thiol-dependent proteases of African trypanosomes. Eur J Biochem 1986; 155: 469-73.
[202] Robertson CD, North MJ, Lockwood BC, Coombs GH. Analysis of the proteinases of Trypanosoma brucei. J Gen Microbiol 1990; 136: 921-5.

[203] Sajid M, McKerrow JH. Cysteine proteases of parasitic organisms. Mol Biochem Parasitol 2002; 120: 1-21.

[204] Troeberg L, Pike RN, Morty RE, Berry RK, Coetzer TH, LonsdaleEccles JD. Proteases from Trypanosoma brucei brucei: purification, characterization and interactions with host regulatory molecules. Eur J Biochem 1996; 238: 728-36.

[205] Caffrey CR, Hansell E, Lucas KD, et al. Active site mapping, biochemical properties and subcellular localization of rhodesain, the major cysteine protease of Trypanosoma brucei rhodesiense. Mol Biochem Parasitol 2001; 118: 61-73.

[206] Lalmanach G, Boulangé A, Serveau C, et al. Congopain from Trypanosoma congolense: drug target and vaccine candidate. Biol Chem 2002; 383: 739-49.

[207] Mbawa ZR, Webster P, Lonsdale-Eccles JD. Immunolocalization of a cysteine protease within the lysosomal system of Trypanosoma congolense. Eur J Cell Biol 1991; 56: 243-50.

[208] Authié E, Muteti DK, Mbawa ZR, Lonsdale-Eccles J, Webster P, Wells CW. Identification of a 33-kilodalton immunodominant antigen of Trypanosoma congolense as a cysteine protease. Mol Biochem Parasitol 1992; 56:103-16.

[209] Chagas J, Authié E, Serveau C, Lalmanach G, Juliano L, Gauthier, F. A comparison of the enzymatic properties of the major cysteine proteinases from Trypanosoma congolense and Trypanosoma cruzi. Mol Biochem Parasitol 1997; 88: 85-94.

[210] Authié E, Boulangé A, Muteti D, Lalmanach G, Gauthier F, Musoke AJ. Immunisation of cattle with cysteine proteinases of Trypanosoma congolense: targeting the disease rather than the parasite. Int J Parasitol 2001; 13: 1429-33.

[211] Serveau C, Boulangé A, Lecaille F, Gauthier F, Authié E, Lalmanach G. Procongopain from Trypanosoma congolense is processed at basic $\mathrm{pH}$ : an unusual feature among cathepsin L-like cysteine proteases. Biol Chem 2003; 384: 921-7.

[212] Lonsdale-Eccles JD, Mpimbaza GWN, Nkhungulu ZRM, et al. Trypanosomatid cysteine protease acitivity may be enhanced by a kininongen-like moiety from host serum. Biochem J 1995; 305: 549-56.

[213] Scory S, Caffrey CR, Stierhof YD, Ruppel A, Steverding D. Trypanosoma brucei: killing of bloodstream forms in vitro and in vivo by the cysteine proteinase inhibitor Z-Phe-Ala-CHN2. Exp Parasitol 1999; 91: 327-33.

[214] Santos CS, Coombs GH, Lima APCA, Mottram JC. Role of the Trypanosoma brucei natural cysteine peptidase inhibitor ICP in differentiation and virulence. Mol Microbiol 2007; 66: 991-1002.

[215] Nikolskaia OV, Lima APCA, Kim YV, et al. Blood-brain barrier traversal by African trypanosomes requires calcium signaling induced by parasite cysteine protease. J Clin Invest 2006; 116: 273947.

[216] Okenu DMO, Opara KN, Nwuba RI, Nwagwu M. Purification and characterization of an extracellularly released protease of Trypanosoma brucei. Parasitol Res 1999; 85: 424-8.

[217] El-Sayed NMA, Donelson JE. African trypanosomes have differentially expressed genes encoding homologues of the Leishmania GP63 surface protease. J Biol Chem 1997; 272: 26742-8.

[218] Grandgenett PM, Otsu K, Wilson HR, Wilson ME, Donelson JE. A Function for a specific zinc metalloprotease of African trypanosomes. PLoS Pathog 2007; 3: 1432-43.

[219] Morty RE, Lonsdale-Eccles JD, Morehead J, et al. Oligopeptidase B from Trypanosoma brucei, a new member of an emerging subgroup of serine oligopeptidases. J Biol Chem 1999a; 274: 2614956.

[220] Morty RE, Authié E, Troeberg L, Lonsdale-Eccles JD, Coetzer TH. Purification and characterization of a trypsin-like serine oligopeptidase from Trypanosoma congolense. Mol Biochem Parasitol 1999b; 102: 145-55.

[221] Morty RE, Lonsdale-Eccles JD, Mentele R, Auerswald EA, Coetzer TH. Trypanosome-derived oligopeptidase B is released into the plasma of infected rodents, where it persists and retains full catalytic activity. Infect Immun 2001; 69: 2757-61. 
[222] Morty RE, Pellé R, Valdász I, Uzcanfa GL, Seeger W, Bubis J. Oligopeptidase B from Trypanosoma evansi: a parasite peptidase that inactivates atrial natriuretic factor in the bloodstream of infected hosts. J Biol Chem 2005; 280: 10925-37.

[223] Morty RE, Troeberg L, Powers JC, Ono S, Lonsdale-Eccles JD, Coetzer THT. A trypanosome oligopeptidase as a target for the trypanocidal agents pentamidine, diminazene and suramin. FEBS Lett 1998; 433: 251-6.

[224] Yao Y, Huang L, Krutchinsky A, Wong ML, Standing KG, Burlingame AL, Wang CC. Structural and functional characterizations of the proteasome-activating protein PA26 from Trypanosoma brucei. J Biol Chem 1999; 274: 33921-30.

[225] Steverding D, Spackman RW, Royle HJ, Glenn RJ. Trypanocidal activities of trileucine methyl vinyl sulfone proteasome inhibitors. Parasitol Res 2005: 95: 73-6.

[226] Branquinha MH, Vermelho AB, Goldenberg S, Bonaldo MC. Characterization of proteinases in trypanosomatids. Braz $\mathrm{J}$ Med Biol Res 1994; 27: 495-9.

[227] Cazzulo JJ, Stoka V, Turk V. The major cysteine proteinase of Trypanosoma cruzi: a valid target for chemotherapy of Chagas' disease. Curr Pharm Des 2001; 7: 1143-56.

[228] Inverso JA, Medina-Acosta E, O'Connor J, Russell DG, Cross GA. Crithida fasciculata contains a transcribed leishmanial surface pep- tidase [gp63] gene homologue. Mol Biochem Parasitol 1993; 57: 47-54.

[229] Schneider P, Glaser TA. Characterization of a surface metalloprotease from Herpetomonas samuelpessoai and comparison with Leishmania major promastigote surface protease. Mol Biochem Parasitol 1993; 58: 277-82.

[230] Matteoli FP, d'Avila-Levy CM, Santos LO, et al. Roles of the endosymbiont and leishmanolysin-like molecules expressed by Crithidia deanei in the interaction with mammalian fibroblasts. Exp Parasitol 2009; 121: 246-53.

[231] Pereira FM, Bernardo PS, Dias Junior PFF, et al. Differential influence of gp63-like molecules in three distinct Leptomonas species on the adhesion to insect cells. Parasitol Res 2009a; 104: 347-53.

[232] Pereira FM, Elias CGR, d'Avila-Levy CM, Branquinha MH, Santos ALS. Cysteine peptidases in Herpetomonas samuelpessoai are modulated by temperature and dimethylsulfoxide-triggered differentiation. Parasitology 2009b, 136: 45-54.

[233] De Souza W, Motta MC. Endosymbiosis in protozoa of the Trypanosomatidae family. FEMS Microbiol Lett 1999; 173: 1-8.

[234] Fampa P, Corrêa-da-Silva MS, Lima DC, Oliveira SMP, Motta MCM, Saraiva EMB. Interaction of insect trypanosomatids with mosquitoes, and fly and the respective insect cell lines. Int $\mathbf{J}$ Parasitol 2003; 33: 1019-26.

(C) Vermelho et al.; Licensee Bentham Open.

This is an open access article licensed under the terms of the Creative Commons Attribution Non-Commercial License (http://creativecommons.org/licenses/by-nc/3.0/) which permits unrestricted, non-commercial use, distribution and reproduction in any medium, provided the work is properly cited. 